Documento de Trabajo - 2021/o6

\title{
Statistical Discrimination and Committees
}

J. Ignacio Conde-Ruiz

(UCM y Fedea)

Juan José Ganuza

(UPF)

Paola Profeta

(Bocconi University y Dondena)

Febrero 2021

\section{fedea}

Las opiniones recogidas en este documento son las de sus autores y no coinciden necesariamente con las de Fedea. 


\title{
Statistical Discrimination And Committees.
}

\author{
J. Ignacio Conde-Ruiz, Juan José Ganuzał, and Paola Profeta ${ }^{\ddagger}$
}

JANUARY $2021 . \S$

\begin{abstract}
We develop a statistical discrimination model where groups of workers (males-females) differ in the observability of their productivity signals by the evaluation committee. We assume that the informativeness of the productivity signals depends on the match between the potential worker and the interviewer: when both parties have similar backgrounds, the signal is likely to be more informative. Under this "homo-accuracy" bias, the group that is most represented in the evaluation committee generates more accurate signals, and, consequently, has a greater incentive to invest in human capital. This generates a discrimination trap. If, for some exogenous reason, one group is initially poorly evaluated (less represented into the evaluation committee), this translates into lower investment in human capital of individuals of such group, which leads to lower representation in the evaluation committee in the future, generating a persistent discrimination process. We explore this dynamic process and show that quotas may be effective to deal with this discrimination trap. In particular, we show that introducing a "temporary" quota allows to reach a steady state equilibrium with a higher welfare than the one obtained in the decentralized equilibrium in which talented workers of the discriminated group decide not to invest in human capital. Finally, if the discriminated group is underrepresented in the worker population (race), restoring efficiency requires to implement a "permanent" system of quotas.
\end{abstract}

KEywords: Statistical discrimination, affirmative actions, committees, quotas and signal accuracy.

JEL classification numbers: C78, D82, K20.

${ }^{*}$ FEDEA and Universidad Complutense de Madrid.

${ }^{\dagger}$ Department of Economics. University Pompeu Fabra.

${ }^{\ddagger}$ Bocconi University and Dondena.

${ }^{\S}$ We wish to thank Antonio Cabrales, David Levine for their comments, as well as the audiences at seminars in Bonn University, Mannheim University and European University Institute. Juan-Jose Ganuza gratefully acknowledges the support of the Barcelona GSE Research, the government of Catalonia, and the Spanish Ministry of Education and Science Through Project ECO2017-89240-P. The usual disclaimers apply. 


\section{INTRODUCTION}

Discrimination occurs when some workers are treated differently than others because of their personal characteristics, such as gender, race, age, nationality, sexual orientation, and so on, that are unrelated to their productivity (Arrow, 1973). Discrimination is not only leading to unequal outcomes, but it may also create efficiency losses: waste of talent, lack of incentives to invest in human capital by the discriminated group, inefficient allocation of resources.

Despite the efforts undertaken for the whole society to fight against discrimination, racial, gender and other minorities disparities still persist. Terms as "systematic racism" are commonly used in the public debate and they point out to an institutional failure that goes beyond the traditional economic arguments for explaining why discrimination may arise in equilibrium. ${ }^{1}$ Small and Pager (2020) argue that organizations may discriminate even though their members do not want to do so, and they are vehicles through which past discrimination (intentional or not) traslates to present discrimination. Along these lines, in this paper we analyze an unintentional discrimination trap linked with the functioning of organizations. We extend a standard statistical discrimination model to analyze a promotion setting in which workers' skills are assessed by committees whose members have different abilities to evaluate workers'signals (they are better at evaluating workers from the same group). The composition of the committee is determined by previous promotion decisions and indirectly by other institutional factors as "technology" (the intrinsic difficulty of the evaluation problem) or demographic factors (group sizes). We will show that this institutional framework may generate persistent discrimination of minority groups that initially were underrepresented in the organization.

We start our analysis considering that population groups have the same size. This a natural assumption for gender groups. Beside having the same weight in the whole population, women are typically underrepresented among top leadership positions. Despite the (slow) reduction of gender gaps in the last decades, the glass ceiling - the invisible barriers which prevent women

\footnotetext{
${ }^{1}$ See Fang and Moro(2011) and Lang and Spitzer (2020) for a review of the classical economic arguments to explain discrimination.
} 
from reaching upper-level positions- is still a dominant phenomenon worldwide. According to the World Economic Forum (2020), globally, only 36\% of senior private sector's managers and public sector's officials are women. Despite the recent progress, the gap to close remains substantial and only a few countries are close to parity. ${ }^{2}$

For closing the gap, we first have to understand what are the barriers that prevent women from achieving top positions. There is a large literature that focuses on supply side arguments ${ }^{3}$ while demand side mechanisms of glass ceiling are less understood. Although there is evidence of stereotype biases (Reuben, Sapienza, and Zingales (2014), Bordalo, Coffman, and Gennaioli (2019) and Bohren, Imas, and Rosenberg (2019)), explicit discriminatory rules have today been removed and the remaining barriers are subtle. In this paper, we show that behind this glass ceiling phenomenon may be an institutional failure, the statistical discrimination undertaken by committess in hirings and promotions. The evaluation and promotion of a worker to a top position is typically taken by a committee. Recent research has shown that the committee's deliberation contributes to the emergence of gender bias (Mengel (2019)). As a result, the selection process is not gender neutral and gender biases emerge in hiring (Goldin and Rouse (2000)) and promotion (Booth et al. (2003)) decisions. We build a theoretical model to explain the gender bias of the committee deliberation and its welfare consequences.

We start by considering a pool of workers that belong to two different groups, for example men and women. We assume that workers' productivity depends on the investment in specific human capital, and then on the incentives provided by the labor market or organizations. ${ }^{4}$ Individuals are heterogenous within groups, as the investment cost differs across workers, but both groups are identical ex-ante in terms of talent, i.e. the distributions of human capital investment costs are

\footnotetext{
${ }^{2}$ Projecting current trends into the future, the World Economic Forum (2020) estimates that the overall global gender gap will close in 99.5 years, on average. If we focus only on the economic component of the gender gap, at the slow speed experienced over the period 2006-2020, it will take 257 years to close it.

${ }^{3}$ Supply arguments as: women dislike competition for promotions (Niederle and Vesterlund (2007)); women avoid the stress and work-life imbalance of top positions (Azmat and Ferrer (2018)); career interruptions due to child caring (Bertrand, Goldin, and Katz (2010)). See Matsa and Miller (2011) for a short review of this literature.

${ }^{4}$ In our setting, human capital is not the observable level of education but a comprehensive concept of investments in increasing the productivity under several dimensions that are difficult to assess: following Arrow (1973), Cornell and Welch (1996) and others, we can include among them steadiness, punctuality, responsiveness, leadership, effort in previous job experience or initiative.
} 
the same in both groups. Workers' productivity is imperfectly observed and it is assessed by an evaluation committee using interviews, past performance, and similar indicators. The outcome of this evaluation process determines workers' payoffs (career opportunities) that we assume to coincide with their expected productivity (firms do not have nor use market power).

The evaluation committee's decision can be regarded as a signal over the productivity of the worker. The main element of our model is that the accuracy of this productivity signal may depend on the composition of the committee and differ across groups. We assume that there is no conflict of interest among committee members and they do not have taste bias preferences for one particular group. Then, when assessing the productivity of the worker, the committee simply aggregates the independent information held by its members and group them into a new signal. Our key assumption that we label as "homo-accuracy" bias is that committee members have better information over the productivity of a worker with whom they share a similar background. ${ }^{5}$ Committees with a higher proportion of men are not adverse per se to women, but they may generate more accurate signals over male candidates than female ones and provide them greater incentives to invest in human capital.

This statistical discrimination in committees is the driving force of persistent gender earnings and promotion gaps in our setting. We consider a dynamic model in which the committees' composition is endogenously determined by the proportion of each group among educated workers in the previous period. This dynamic link generates multiplicity of steady state equilibria with symmetric equilibria in which workers' strategies are the same in both groups and asymmetric equilibria in which in one group, the talented workers invest in human capital and in the other they don't invest. This asymmetric equilibrium may arise if the initial condition is such that one group is underrepresented in the committee. Then individuals in this underrepresented group are poorly evaluated, they choose to make lower investment in human capital, which leads to lower representation in the evaluation committee in the future, generating a persistent discrimination

\footnotetext{
${ }^{5}$ We borrow our "homo-accuracy" assumption from the statistical discrimination literature. In particular, Cornell and Welch (1996) assume that "employers can judge job applicants' unknown qualities better when candidates belong to the same group", where groups are defined broadly to include language, religious belief, ethnic background, race, sex, sexual preference, neighborhood upbringing, schooling, or membership in social organizations.
} 
process. We explore this dynamic process and show that affirmative actions policies, such as quotas in the evaluation committees, may be effective to deal with this inefficient discrimination trap. The main result of the paper is that quotas, even when non permanent, can move from an inefficient asymmetric equilibria to a symmetric efficient equilibria in which talented workers of both groups invest in human capital, generating total welfare gains. However, we also show that quotas may reduce welfare if imposed in non favorable environments, in which a symmetric equilibrium with a high level of human capital investment in both groups is not feasible.

There is nothing inherent in the model that refers exclusively to gender inequality. Our results could be apply, for example, to race discrimination as well. The only relevant parameter in the baseline model that refers to gender discrimination is the assumption that the proportion of workers of the discriminated group is half the total workers' population. We will extend the baseline model (for considering race) to the case in which there exists an arbitrary proportion of the discriminated group. We show that quotas are likely to play a more important role when the discriminated group is less than half the population since the set of parameters for which an inefficient discriminatory trap may arise is larger than in the case of gender. Moreover, we also show that for restoring efficiency, in this case it may be necessary to implement a permanent system of quotas.

The literature on statistical discrimination goes back to the early seventies. Phelps (1972) shows that workers with the same productivity are treated differently, when people do not have full information about an individual's relevant work characteristics and use group statistics as a proxy. In this line, our work is related to Aigner and Cain (1977), Lundberg and Startz (1983), Cornell and Welch (1996) and Morgan and Vardy (2009), that analyze settings in which there are no ex-ante productivity differences between different population groups, but workers' productivity is imperfectly observed by employers with different precision, generating discrimination outcomes and inefficiencies. We contribute to this literature by analyzing the role of committees in this accuracy bias and show that statistical discrimination in committees can lead to an inefficient discriminatory trap that can be overcome by affirmative action policies. 
Another branch of the literature starting with Arrow (1973) includes Foster and Vohra (1992), Coate and Loury (1993) and Moro and Norman (2004) among others. They analyze other types of discrimination driven by "self-confirming stereotypes". Minority workers invest less in human capital since they (correctly) anticipate that employers will threat them worst. This effect can also arise when the evaluation of workers' productivity is done by a committee. Typically, the committee wants to minimize decision errors in its evaluation and should thus take into account the priors over the productivity of each group, opening the possibility of discrimination due to "self-confirming stereotypes". We extend our base model to analyze how priors affect committee decisions and show that minority groups can be adversely treated through this mechanism. We also show that when the committee optimally use the prior information in its decisions, the symmetric good equilibria in which talented workers of both groups invest in human capital is most likely to arise.

The closest papers to ours are Athey et al (2000) and Siniscalchi and Veronesi (2020) which study a related intertemporal dynamic links but focus on a different mechanisms. Athey et al (2000) analyzes a firm in which employees, as in our model, belong to two different groups and differ in their productivity. There are entry-level and upper-level positions. In each period, a proportion of entry-level employees is promoted. The dynamic link is that productivity may increase with mentoring, and an employee receives more mentoring the higher is the share of her type among the upper level employees. The authors analyze optimal promotion policies and characterize different steady states. As in our setting, long term equilibria in which upper level positions are dominated by a group may arise. Beside the mentoring mechanism, our approach differ in which we deal with the worker investment in human capital and the asymmetric equilibria are likely to lead to an inefficient allocation of talent. Therefore, the positive discriminatory policies may not only have long term impact, as in Athey et al (2000), but they can also restore efficiency. Siniscalchi and Veronesi (2020) focuses on academic labor market and points out an unintentional discrimination trap linked to the so-called "self image bias". Research evaluators are biased towards young researchers with similar characteristics to them. The authors build 
up an overlapping-generations model with two groups of researchers with equally desirable (but a little bit different) research characteristics and identical ex-ante productivity distributions. If one group is slightly overrepresented into the evaluators, this group (and its specific research characteristics) may dominate forever. We describe a similar institutional dynamic failure in a setting in which productivity is endogenous and with a different driving force. Under "self image bias", referees positively evaluate researchers with similar characteristics to them. On the contrary, our "homo-accuracy bias", only affects to the quality of the screening process rather than its outcome.

Our paper is also broadly related to the literature on information aggregation and communication in committees. ${ }^{6}$ In our benchmark model, the committee is a group of privately informed individuals with common interests deciding over two possible evaluation outcomes. We assume that the committee takes the best option given the signals revealed. In this frictionless setting, as in Coughlan (2000), it is optimal for committee members to reveal all their information, since revealing a private signal cannot make the outcome worse. Then, unlike the literature on voting rules and information aggregation (early contributions include Austen-Smith and Banks (1996) and Feddersen and Pesendorfer (1996)), we are ignoring the strategic behaviour among committee members that arises when it is costly to adquire or reveal information, or if committee members are limited to cast a vote. Regarding this last point, we consider an extension of the model in which the decision of the committee is taken using a majority rule with an arbitrary threshold.

The paper is organized as follows: the next section presents the benchmark model of human capital investment under imperfect information; section three shows the role of committees in statistical discrimination; section four introduces the basic model into a dynamic setting and shows that a discrimination trap may arise and quotas may be an effective remedy to restore efficiency; section five extends the model to analyze race discrimination (the case in which the population sizes of groups are not equal); section six analyzes several extensions and section seven concludes.

\footnotetext{
${ }^{6}$ For a nice review of this literature see Austen-Smith and Feddersen (2009) and the recent contribution of Osborne et al (2020).
} 


\section{Simple Model of Human Capital Investment}

Workers (candidates) are risk neutral and their productivity depends on their investment decisions in human capital. In particular, a worker decides whether to invest in human capital or not, i.e. $e \in\{I, N\}$. Investing entails a fixed $\operatorname{cost} c \geq 0$, but leads to high productivity $\bar{\theta}$, whereas not investing entails no fixed cost but is linked with low productivity $\underline{\theta}{ }^{7}$

Workers may be of three different types, depending on the size of the fixed cost incurred in case of investment in human capital. With ex ante probability $\frac{1-\alpha}{2}$ a worker has a fixed cost $c=\infty$. As a consequence, independently of labor incentives, this type of worker will never invest

and have low productivity $\underline{\theta}$. With probability $\frac{1-\alpha}{2}$, a worker has a fixed cost $c=0$. This type of worker will always invest and have a high productivity $\bar{\theta}$. Finally, with a probability $\alpha$, a worker faces an intermediate fixed cost $\widehat{c}$, with $0<\widehat{c}<\bar{\theta}-\underline{\theta}$. We denote these workers as "strategic" types, since their decision of investing in human capital will depend on the labor incentives. ${ }^{8}$ Notice that for $\widehat{c}<\bar{\theta}-\underline{\theta}$, it is efficient for "strategic" workers to invest in human capital.

Workers learn their types before they decide whether or not to invest in human capital. Workers types are private information. Their productivity is imperfectly observed by an evaluation committee using interviews, past performance and other mechanisms. We summarize this evaluation process with a binary signal $s$, where $s \in\left\{s_{H}, s_{L}\right\}$. We start by taking this information structure as exogenous. The signal's realization depends on the underlying productivity of the worker as follows:

\begin{tabular}{r|cc}
$\operatorname{Pr}(s \mid \theta)$ & $\bar{\theta}$ & $\underline{\theta}$ \\
\hline$s_{H}$ & $\frac{1+\gamma_{\bar{\theta}}}{2}$ & $\frac{1-\gamma_{\underline{\theta}}}{2}$ \\
$s_{L}$ & $\frac{1-\gamma_{\bar{\theta}}}{2}$ & $\frac{1+\gamma_{\underline{\theta}}}{2}$
\end{tabular}

That is, if the worker has high productivity, the evaluation will be positive, $s_{H}$, with probability $\frac{1+\gamma_{\bar{\theta}}}{2}$. Similarly, if the productivity is low, the evaluation will be negative, $s_{L}$, with probability $\frac{1+\gamma_{\underline{\theta}}}{2}$. Notice that the evaluation committee may make mistakes (signal has noise) and independently of the worker' productivity, both signal realizations may take place. For tractability, we

\footnotetext{
${ }^{7}$ In section 4 , we analyze an extension of the benchmark model in which we consider a continuous level of effort $e$ and uncertainty (the map between effort and productivity is not deterministic).

${ }^{8}$ This structure of types is inspired by the credit reputation model of Diamond (1989).
} 
assume symmetry $\gamma_{\bar{\theta}}=\gamma_{\underline{\theta}}=\gamma \in[0,1]$, where $\gamma$ represents the accuracy of the signal, with a higher $\gamma$ implying a more informative signal. More specifically, with $\gamma=0$ the signal is non-informative, the realization of the signal is not correlated with productivity. On the contrary, with $\gamma=1$ the signal is fully informative since it reveals the underlying productivity of the worker. Finally, we assume that workers payoffs coincide with the expected worker productivity given the outcome of the evaluation process (the signal realization $s$ ). In words, we assume that there is no "economic discrimination" since two workers with identical (expected) productivity are paid equally. ${ }^{9}$

The timing of the game is as follows.

1. Nature chooses the types of workers (the fixed cost $c$ of acquiring human capital).

2. Each worker chooses whether or not to invest in human capital which determines her productivity.

3. The evaluation committee chooses the signal $s \in\left\{s_{H}, s_{L}\right\}$ on the worker productivity according to the information structure described above.

4. Workers payoffs are realized according to their expected productivity given $s$.

\subsection{The Market Game. Expected workers' payoffs}

As usual, we solve the game backwards. Thus, we start by determining the workers' payoffs given the signal generated by the evaluation committee $s$. We have assumed that workers' total payoffs are their expected productivity:

$$
w(s)=\underline{\theta} \operatorname{Pr}(\underline{\theta} \mid s)+\bar{\theta} \operatorname{Pr}(\bar{\theta} \mid s)=\underline{\theta}+(\bar{\theta}-\underline{\theta}) \operatorname{Pr}(\bar{\theta} \mid s) .
$$

for simplicity we assume $\underline{\theta}=0$, then

$$
w\left(s_{H}\right)=\bar{\theta} \operatorname{Pr}\left(\bar{\theta} \mid s_{H}\right) \text { and } w\left(s_{L}\right)=\bar{\theta} \operatorname{Pr}\left(\bar{\theta} \mid s_{L}\right)
$$

\footnotetext{
${ }^{9}$ For the main results it is not needed that the payoffs coincide with the expected productivity but that they should be proportional to it. In fact, the model is compatible with a promotion setting within an organization or with a wage bargaining process in a labor market. However, for this later case, we have to additionally assume that not only the outcome but also the details of the evaluation processes are "common knowledge" (observable by the market).
} 
Given these salaries, which will be the investment strategy chosen by workers in equilibrium? Or, in other words, under which circumstances the strategic workers are going to invest in human capital? Solving the game and answering these questions require characterizing the Perfect Bayesian Equilibrium (PBE). A PBE is a set of strategies and beliefs such that, at any stage of the game, strategies are optimal given the beliefs, and the beliefs are obtained from equilibrium strategies and observed actions using Bayes' rule.

The investment strategy will depend on the type of the worker: the type with $c=\infty$ will never invest, while the type with $c=0$ will always do it. We are then left to discuss what the strategic type with $0<\widehat{c}<\bar{\theta}$ is going to do. In order to do so, we start by determining the expected payoffs given the workers' investment decisions, the accuracy of the evaluation committee $\gamma$ and the prior belief $\operatorname{Pr}(\bar{\theta})=p$.

$$
\begin{aligned}
& W_{\bar{\theta}}(\gamma, p)=\frac{1+\gamma}{2} w\left(s_{H}\right)+\frac{1-\gamma}{2} w\left(s_{L}\right) \\
& W_{\underline{\theta}}(\gamma, p)=\frac{1+\gamma}{2} w\left(s_{L}\right)+\frac{1-\gamma}{2} w\left(s_{H}\right)
\end{aligned}
$$

Therefore, the incentives to invest in human capital are driven by the incremental expected pay-off between high and low productivity.

$$
W_{\bar{\theta}}(\gamma, p)-W_{\underline{\theta}}(\gamma, p)=\gamma \bar{\theta}\left(\operatorname{Pr}\left(\bar{\theta} \mid s_{H}\right)-\operatorname{Pr}\left(\bar{\theta} \mid s_{L}\right)\right)
$$

Lemma 1 Incentives to invest in human capital, $W_{\bar{\theta}}(\gamma, p)-W_{\underline{\theta}}(\gamma, p)$, are increasing in the accuracy of the signal $\gamma$.

In words, higher accuracy makes the correlation between signal realization $s \in\left\{s_{H}, s_{L}\right\}$ and productivity $\{\bar{\theta}, \underline{\theta}\}$ stronger. This higher correlation increases (decreases) the probability of receiving a positive signal $s_{H}$ for a high (low) productivity worker and also increases (decreases) the payoffs of $s_{H}, w\left(s_{H}\right)=\bar{\theta} \operatorname{Pr}\left(\bar{\theta} \mid s_{H}\right)\left(s_{L}, w\left(s_{L}\right)=\bar{\theta} \operatorname{Pr}\left(\bar{\theta} \mid s_{L}\right)\right)$. These two forces increase the payoffs of high productivity and reduces the payoffs of low productivity, leading to higher incentives to invest in human capital.

There exist two possible PBE in pure strategies: i) High Human Capital (HHC) equilibrium in which strategic workers choose to invest in human capital, since the incremental expected 
pay-off between high and low productivity compensates the cost of acquiring human capital, i.e $W_{\bar{\theta}}(\gamma, p)-W_{\underline{\theta}}(\gamma, p) \geq \widehat{c}$. ii) Low Human Capital Equilibrium (LHC) in which strategic workers prefer not to invest in human capital, since $W_{\bar{\theta}}(\gamma, p)-W_{\underline{\theta}}(\gamma, p) \leq \widehat{c}$.

With perfect information $\gamma=1$, as salaries are equal to workers' productivity, strategic workers invest since it is efficient to do so $\left(W_{\bar{\theta}}(\gamma, p)-W_{\underline{\theta}}(\gamma, p)=\bar{\theta} \geq \widehat{c}\right)$. Given this and that incentives to invest are increasing in $\gamma$ (Lemma 1), HHC requires a high enough accuracy $\gamma \geq \underline{\gamma}$ to arise, while LHC requires a low enough accuracy $\gamma \leq \bar{\gamma}$ to hold. The next step is to characterize both equilibria by computing these two thresholds.

\subsection{High Human Capital (HHC) Equilibrium}

Perfect Bayesian Equilibrium requires that priors and beliefs are consistent with strategies. Then, in the HHC equilibrium the prior that the worker has high productivity is $p=\operatorname{Pr}(\bar{\theta})=$ $\frac{1-\alpha}{2}+\alpha=\frac{1+\alpha}{2}$ (given that $c=0$ and strategic types invest). Then, the incentive compatibility condition becomes

$$
W_{\bar{\theta}}\left(\gamma, \frac{1+\alpha}{2}\right)-W_{\underline{\theta}}\left(\gamma, \frac{1+\alpha}{2}\right) \geq \widehat{c}
$$

Applying bayes rule, we can rewrite the incentive compatibility condition in terms of $\gamma$, as follows:

$$
\gamma \geq \underline{\gamma}=\left(\frac{\widehat{\widehat{c}}}{1-\alpha^{2}\left(1-\frac{\widehat{\bar{c}}}{\bar{\theta}}\right)}\right)^{\frac{1}{2}} .
$$

where $W_{\bar{\theta}}\left(\underline{\gamma}, \frac{1+\alpha}{2}\right)-W_{\underline{\theta}}\left(\underline{\gamma}, \frac{1+\alpha}{2}\right)=\widehat{c}^{10}$ As we anticipate, if the level of accuracy of the public signal $\gamma$ is large enough, strategic workers have incentives to invest in their human capital and the HHC equilibrium exists. ${ }^{11}$

\footnotetext{
${ }^{10}$ Applying the Bayes' rule we can rewrite the expected pay-off function as follows $W_{\bar{\theta}}\left(\underline{\gamma}, \frac{1+\alpha}{2}\right)-W_{\underline{\theta}}\left(\underline{\gamma}, \frac{1+\alpha}{2}\right)=$ $\frac{1+\underline{\gamma}}{2}(1+\alpha) \bar{\theta} \underline{\gamma}\left(\frac{\frac{1+\underline{\gamma}}{2}}{1-\alpha+2 \alpha \frac{1+\underline{\gamma}}{2}}-\frac{\frac{1-\underline{\gamma}}{2}}{1+\alpha-2 \alpha \frac{1+\underline{\gamma}}{2}}\right)$. Simplifying this expression, the binding incentive compatibility condition becomes $\bar{\theta} \frac{\underline{\gamma}^{2}\left(1-\alpha^{2}\right)}{1-\alpha^{2} \underline{\gamma}^{2}}=\widehat{c}$. After some computation, we get $\underline{\gamma}$.

${ }^{11}$ Interestingly, the cut-off $\underline{\gamma}$ is increasing in $\frac{\widehat{c}}{\bar{\theta}}$. In other words, the HHC is more likely to arise if the investment in human capital is more profitable.
} 


\subsection{Low Human Capital (LHC) Equilibrium}

The analysis is analogous to the previous one. Suppose now that the strategic type chooses not to invest. Then, in such a case, priors that a worker has high productivity are $p=\operatorname{Pr}(\bar{\theta})=\frac{1-\alpha}{2}$ (only the $c=0$ type invests) and the incentive compatibility condition is

$$
W_{\bar{\theta}}\left(\gamma, \frac{1-\alpha}{2}\right)-W_{\underline{\theta}}\left(\gamma, \frac{1-\alpha}{2}\right) \leq \widehat{c} .
$$

We can rewrite the incentive compatibility condition in terms of $\gamma$.

$$
\gamma \leq \bar{\gamma}=\left(\frac{\widehat{\widehat{c}}}{1-\alpha^{2}\left(1-\frac{\widehat{c}}{\bar{\theta}}\right)}\right)^{\frac{1}{2}}
$$

Where $W_{\bar{\theta}}\left(\bar{\gamma}, \frac{1-\alpha}{2}\right)-W_{\underline{\theta}}\left(\bar{\gamma}, \frac{1-\alpha}{2}\right)=\widehat{c} .{ }^{12}$ Contrary to the previous case, the LHC equilibrium arises only if the level of accuracy $\gamma$ is low enough.

\subsection{Equilibrium Analysis}

The next proposition uses the incentive compatibility conditions of the HHC and LHC equilibria to provide a full characterization of the perfect bayesian equilibrium of the game in terms of the accuracy of the signal. Notice that the equilibrium is characterized by a single cut-off $\underline{\gamma}=\bar{\gamma}=\gamma^{*}$ where $\gamma^{*}=\left(\frac{\frac{c}{\bar{\theta}}}{1-\alpha^{2}\left(1-\frac{c}{\bar{\theta}}\right)}\right)^{\frac{1}{2}}$ and then, there is no multiplicity of equilibria.

Proposition 1 When the level of accuracy $\gamma$ is lower than $\gamma^{*}$, the only equilibrium is the LHC, whereas, when the level of accuracy is higher than $\gamma^{*}$, the only equilibrium is the HHC.

The uniqueness of the pure strategy equilibrium is due to the symmetry of the information structure $\gamma_{\bar{\theta}}=\gamma_{\theta}=\gamma$. In the appendix, we analyze an asymmetric information structure that generates different thresholds for the HHC and LHC equilibria, where $\underline{\gamma}<\bar{\gamma}$. In such a case, if $\underline{\gamma}<\gamma<\bar{\gamma}$ then both LHC and HHC equilibria may exist and the multiplicity of equilibria arises.

\footnotetext{
${ }^{12}$ Applying the Bayes rule we obtain $W_{\bar{\theta}}\left(\bar{\gamma}, \frac{1-\alpha}{2}\right)-W_{\underline{\theta}}\left(\bar{\gamma}, \frac{1-\alpha}{2}\right)=(1-\alpha) \bar{\theta} \bar{\gamma}\left(\frac{\frac{1+\bar{\gamma}}{2}}{1+\alpha-2 \alpha \frac{1+\bar{\gamma}}{2}}-\frac{\frac{1-\bar{\gamma}}{2}}{1-\alpha+2 \alpha \frac{1+\bar{\gamma}}{2}}\right)$. If we simplify this expression, we obtain the same condition than in the HHC equilibrium $\bar{\theta} \frac{\bar{\gamma}^{2}\left(1-\alpha^{2}\right)}{1-\alpha^{2} \bar{\gamma} 2}=\widehat{c}$. Therefore, the thresholds of both equilibria coincide $\bar{\gamma}=\underline{\gamma}$.
} 
When we compute the workers' payoffs given the signal generated by the evaluation committee, we do not take into account that employers may update their believes over workers' productivity during their careers. In other words, a high and a low productivity worker with the same evaluation will start obtaining the same wage but will end-up their careers with different salaries. ${ }^{13}$ The simplest way to take this into account in our model is by assuming that there exists an additional final period in which the payoffs of the workers coincide with their productivity.

Then, the new payoff functions would be $\widetilde{W}_{\bar{\theta}}(\gamma, p)=W_{\bar{\theta}}(\gamma, p)+\delta \bar{\theta}$ and $\widetilde{W}_{\underline{\theta}}(\gamma, p)=W_{\underline{\theta}}(\gamma, p)+$ $\delta \underline{\theta}$, where $\delta$ is an arbitrary discount factor. The incentive compatibility constraint under these new functions, becomes

$$
\widetilde{W}_{\bar{\theta}}(\gamma, p)-\widetilde{W}_{\underline{\theta}}(\gamma, p)=W_{\bar{\theta}}(\gamma, p)-W_{\underline{\theta}}(\gamma, p)+\delta(\bar{\theta}-\underline{\theta}) \geq \widehat{c} .
$$

Notice that this incentives compatibility is identical to the one of the baseline model with a investment cost $\widehat{c}-\delta(\bar{\theta}-\underline{\theta})$. Then, Proposition 1 also characterizes the equilibrium of this case but with a different cut-off point $\widetilde{\gamma}^{*}$. As $\gamma^{*}$ is decreasing in $\widehat{c}, \widetilde{\gamma}^{*}<\gamma^{*}$. The HHC (LHC) equilibrium would arise in this case, for a larger (smaller) set of parameters since there is an additional benefit of investing in human capital.

\section{Endogenous Information Structures and Statistical Discrimination}

The previous section is devoted to explain the relationship between incentives to invest in human capital and the informativeness of the workers' productivity signals. We now move to the core of our paper and investigate how the accuracy of the productivity signals is determined. Our central idea is that the information structure summarizes the decision process of an evaluation

\footnotetext{
${ }^{13}$ An extensive literature in labor economics documents that employers learn workers' productivity over time and they analyze the process of learning. The seminal paper by Altonji and Pierret (2001) shows that firms learn about productivity of young workers. This learning process implies that, in a context of statistical discrimination based on osbservable characteristics, such as education, the easily observed variables become less important while the hard-to-observe ones rise their relevance. Although learning may be asymmetric (Pinkston, 2009), that is the current employer may have superior information about workers' productivity than other employers, the empirical evidence seems to suggest that learning appears to be mostly symmetric (Schonberg, 2007). Yet the learning process is not easy, especially if workers' productivity evolves over time: Kahn and Lange (2014) shows that learning the workers' dynamic productivity by firms is imperfect. For empirical evidence on statistical discrimination see Lesner (2018), Pallais (2014), Roland et al (2013).
} 
committee. In other words, the realization of the binary signal in the previous model $s \in\left\{s_{H}, s_{L}\right\}$ is the positive or negative outcome of the worker's productivity evaluation process undertaken by a committee. We assume that the accuracy of the signal $s$ follows a function $\gamma=h(\phi, \pi)$ which depends on the composition of the committee $\phi$ andon a parameter $\pi$ that measures the difficulty of obtaining and aggregate information and of taking the decision. In this section, we will develop this idea in a setting in which workers (and managers in the committee) differ also along another dimension besides the cost type.

Consider that workers belong to one of the following two groups: $m$, for example men and $f$, for example women. We assume that $\rho$ is the proportion of individuals of group $m$ in the population and therefore $(1-\rho)$ is the proportion of individuals of group $f$. For simplicity, and for a more direct interpretation of our results in terms of gender discrimination, we assume that $\rho=\frac{1}{2}$. In the extension section, we discuss the case of $\rho<\frac{1}{2}$.

The two groups may differ in the accuracy of their productivity signals. The representation of each worker's group in the evaluation committees determines the accuracy of the signals of such particular group. In what follows, we formalize this idea. Let $\phi^{m}$ be the proportion of male managers in the selection committee, and $\phi^{f}$ the proportion of females, where $\phi^{m}+\phi^{f}=1$. Let $\gamma^{m}=h^{m}\left(\phi^{m}, \pi\right)$ and $\gamma^{f}=h^{f}\left(\phi^{f}, \pi\right)$ be the accuracy of the productivity signal of male (female) workers respectively.

We assume that the accuracy function $h^{j}\left(\phi^{j}, \pi\right)$ is characterized by three properties: i) Homoaccuracy, $h^{j}\left(\phi^{j}, \pi\right)$ is increasing in $\phi^{j}$. ii) Symmetry, $\gamma^{m}=h^{m}\left(\phi^{m}, \pi\right)=\gamma^{f}=h^{f}\left(\phi^{f}, \pi\right)$ if $\phi^{m}=\phi^{f}$. iii) Screening Complexity, if $\pi>\pi^{\prime}$ then $h^{j}\left(\phi^{j}, \pi\right) \geq h^{j}\left(\phi^{j}, \pi^{\prime}\right)$ for all $\phi^{j} \in(0,1)$.

We label i) as the "homo-accuracy" assumption: the accuracy of each group of workers is increasing in the proportion of such group in the evaluation committee, and consequently decreasing in the proportion of the other group. There is supportive evidence of gender non-neutrality in selection process, because men (women) evaluate men (women) in a more accurate way. ${ }^{14}$ As-

\footnotetext{
${ }^{14}$ For example, Pinkston (2003) finds strong evidence that employers receive less-accurate initial signals from women than from men, even when comparing men and women in the same job. Lang (1986) in a theoretical model and under the assumption that communication is more costly between dissimilar groups, shows that the competitive market when interaction is required, the cost will be borne by the minority group. A experiment by Ferrari et al.
} 
sumption of symmetry ii) is made for tractability, to allow us to use the same function $h(\phi, \pi)$ for both groups. Finally, according to assumption iii), the parameter $\pi$ orders the evaluation processes for their screening complexity. This captures that in some jobs or environments it is easier to infer workers' productivity than in others.

In order to better understand this characterization, in the next subsection we provide a specific committee evaluation process that generates an accuracy function $h(\phi, \pi)$ that satisfies the three properties and it is consistent with the information structure used in the main model.

\subsection{A Committee Evaluation Process and Its Accuracy Function}

Assume that a committee of $N$ members is in charge of evaluating workers' productivity. With probability $\pi \sigma(\pi)$ an individual member $i$ of the committee observes the productivity of a worker of her own group (of a different group), and with probability $1-\pi \sigma(1-\pi)$, she does not observe anything. We assume that $\sigma>1$, that is, when a worker of group $j$ is evaluated by a member of her group $j$, her productivity is observed with higher probability.

The committee decision over a high productivity worker of group $j$ is as follows. With probability $\Gamma=1-(1-\pi \sigma)^{\phi^{j} N}(1-\pi)^{\left(1-\phi^{j}\right) N}$, the productivity is observed by at least one member of the committee and the correct decision is taken $\left(s_{H}\right.$ is realized). With probability $1-\Gamma$, the productivity is not observed and $s \in\left\{s_{H}, s_{L}\right\}$ is chosen randomly with probability $\frac{1}{2}$.

Then, the probability of a positive signal for a high productivity worker is $\Gamma$ (the probability that the productivity is observed) plus $(1-\Gamma) \frac{1}{2}$ (the probability that the productivity is not observed and the outcome of the lottery is positive), $\operatorname{Pr}\left(s_{H} \mid \bar{\theta}\right)=\Gamma+(1-\Gamma) \frac{1}{2}=\frac{1+\Gamma}{2}$. By symmetry, $\operatorname{Pr}\left(s_{L} \mid \underline{\theta}\right)=\frac{1+\Gamma}{2}$. The accuracy function $\gamma^{j}=h^{j}\left(\phi^{j}, \pi\right)$ is determined by the conditional

(2015) find that, although on average there is no bias per se in favour of a group in the promotion process in companies, the evaluators assign different weights to signals such as occupational experience and education of a male and female candidate. They find that the informativeness of the productivity signals depends on the match between the candidate and the evaluator, which in turn may be captured by having the same gender. The accuracy in evaluating candidates of a different gender may depend on the existence of gender segregated networks, gender segregated tasks in jobs, or on the presence of gender stereotypes. Finally, in another recent paper using a detailed matched employer-employee longitudinal data set for Italy, Flabbi et al. (2019) obtain two interesting results on the impact of having a female CEO: i) it reduces the gender wage gap at the top of the wage distribution and ii) it performs better, the higher the fraction of women in the firm's workforce. 
distribution $\operatorname{Pr}(s \mid \theta)$ and generates the information structure used in the main model

\begin{tabular}{r|cc}
$\operatorname{Pr}(s \mid \theta)$ & $\bar{\theta}$ & $\underline{\theta}$ \\
\hline$s_{H}$ & $\frac{1+\gamma}{2}$ & $\frac{1-\gamma}{2}$ \\
$s_{L}$ & $\frac{1-\gamma}{2}$ & $\frac{1+\gamma}{2}$
\end{tabular}

where $\gamma^{j}=h^{j}\left(\phi^{j}, \pi\right)=\Gamma=1-(1-\pi \sigma)^{\phi^{j} N}(1-\pi)^{\left(1-\phi^{j}\right) N}$. This accuracy function is consistent with our characterization. i) As $\frac{\partial \Gamma}{\partial \phi^{j}} \geq 0$, the "homo-accuracy" assumption is satisfied. ii) Symmetry holds by construction $\gamma^{m}=h^{m}\left(\phi^{m}, \pi\right)=\gamma^{f}=h^{f}\left(\phi^{f}, \pi\right)$ if $\phi^{m}=\phi^{f}$. iii) Screening Complexity also holds since $\frac{\partial \Gamma}{\partial \pi}>0$ and then $\pi>\pi^{\prime}$ implies $h^{j}\left(\phi^{j}, \pi\right) \geq h^{j}\left(\phi^{j}, \pi^{\prime}\right)$ for all $\phi^{j} \in(0,1)$.

Beyond this example of endogenous accuracy function, there are two important underlying features in the way in which we model the committee decision process. We assume that there is no conflict of interest among committee members and that their only task is to aggregate the information to reach the best possible decision. Under these assumptions, if we take as given that a committee member better evaluates candidates of her own group (she receives more informative independent signals over the productivity of the worker), then more aggregate information and better decisions should be expected the larger is the proportion of committee members of the same group of the candidate. ${ }^{15}$ However, we have to point out that the committee decision process previously analyzed is not fully optimal since the committee does not use the priors over the productivity of the candidate when taking the decision. We tackle this question in the extension section, where we also consider an alternative committee decision process using a simple voting mechanism.

\subsection{Statistical Discrimination}

Proposition 1 and our characterization of $h(\phi, \pi)$ jointly deliver the result that the group that has a larger proportion in the evaluation committee has more incentives to invest in human capital.

\footnotetext{
${ }^{15}$ Beside this natural intuition, as far as we know, there are no models that combine group decision making and aggregation of information in a setting of common interest and members with different quality signals, see Roux and Sobel (2015) for a recent contribution to this literature.
} 
Proposition 2 If $\phi^{f}<\frac{1}{2}$ then, $\gamma^{m}>\gamma^{f}$ which implies: i) Men invest weakly more in human capital than women. ii) Conditional on receiving a positive evaluation, $s_{H}$, men's wages are weakly higher.

In words, the group that has a smaller proportion in the evaluation committee has a noisier signal of her productivity and then it has: i) less incentives to invest in human capital ${ }^{16}$ and ii) a lower wage in case of $s_{H}$, meaning that women with good evaluations receive lower salaries than men with positive evaluations. Hence, statistical discrimination may lead to an inefficient allocation of resources and it induces an unfair distribution of salaries.

Then, our model predicts that if women are underepresented in committees, they have less incentives to invest in human capital. In our context, following Becker (1975), human capital corresponds to any stock of knowledge or characteristics of the worker (either innate or acquired) that contribute to his or her "productivity". Some of these characteristics are observable, as the years of schooling, but many others are not, such as training, investing in learning new skills (or perfecting old ones) while on the job, or attitudes towards work. As we said before, we are focusing on these unobservables factors, assuming that observable characteristics are equal among groups. In fact, in most of the countries women invest even more than men in the observable characteristics of human capital, such as years of schooling. Women may decide to invest more than men in observable characteristics, because the returns on investment in non observable characteristics are more risky or uncertain.

\section{The Dynamic Model and the Role of Quotas}

Statistical discrimination not only creates a distributional conflict between the minority and majority groups, but it may also lead to an inefficient allocation of talents, by not providing enough incentives to the strategic worker of the minority group to invest in human capital. In our

\footnotetext{
${ }^{16}$ This result goes in line with Lundberg and Startz (1983). As we do, they assume that worker's productivity is determined by their investment in human capital and the informativeness of the productivity signals differs across groups. As in i) of Proposition 2, they show that workers with the higher signal noise invest less than workers with the lower signal noise.
} 
simple setting, in which we assume that $\bar{\theta} \geq \widehat{c}$, the efficient allocation requires (if it is feasible) $)^{17}$ that in both groups the strategic workers invest in human capital (i.e both groups are in the HHC equilibrium).

In this section, we take a normative approach, we analyze these potential inefficiencies and we characterize policies that enhance total welfare. In order to do so, we need a model where the composition of the committee is endogenously determined. We undertake this by embodying our model in a very simple dynamic setting.

We start by considering that every stage of the dynamic game is identical to our static model. There is no career concern, workers live one period ${ }^{18}$ and only an infinitesimal proportion of the high productivity workers becomes member of the selection committee. ${ }^{19}$ Then, the dynamic link is that the human capital investment decisions of period $t-1$ determine the composition of the evaluation committee and the accuracy for each population group at period $t$. In particular, let $\phi_{t-1}^{f}\left(\phi_{t-1}^{m}=1-\phi_{t-1}^{f}\right)$ be the proportion of females (males) among the group of workers who have invested in human capital at $t-1$, and also the proportion of females (males) in the selection committee at period $t$. Then, $\gamma_{t}^{f}\left(\gamma_{t}^{m}\right)$ is increasing (decreasing) in $\phi_{t-1}^{f}\left(\phi_{t-1}^{f}\right)$

$$
\gamma_{t}^{j}=h\left(\phi_{t-1}^{j}, \pi\right) \forall t
$$

We start with an initial condition $\phi_{0}^{f} \leq \frac{1}{2}$ that determines $\gamma_{1}^{f}=h\left(\phi_{0}^{f}, \pi\right)$. The next Lemma characterizes the dynamic equilibrium paths.

Lemma 2 A steady state is reached in one or two periods. i) If $\gamma_{1}^{f} \geq \gamma^{*}$, a symmetric HHC

\footnotetext{
${ }^{17}$ The feasibility of having the two groups in the good equilibrium HHC depends on the accuracy function $h(\phi, \pi)$ that maps the composition of evaluation committees into the accuracy of productivity signals. For example, increasing the proportion of women $\phi^{f}$ in the evaluation committee, increases $\gamma^{f}$ and the incentives to invest for women, but also reduces $\gamma^{m}$ and the incentives to invest for men (negative externality). Therefore, increasing $\phi^{* f}$ in the evaluation committee will increase total welfare if women invest in human capital (and before not) $\gamma^{f}=h\left(\phi^{* f}, \pi\right) \geq \gamma^{*}$, while keeping men's incentives in investing in human capital $\gamma^{m}=h\left(\phi^{* m}, \pi\right) \geq \gamma^{*}$. Keeping both groups in the HHC equilibrium is feasible only if the screening process is not too complex, if $\pi$ is large enough.

${ }^{18}$ We can also make the alternative assumption that workers live more than one period but their careers are fully determined by their investment decisions and the evaluation outcomes of the first period. In the same line, we could introduce additional periods in which payoffs are converging to real productivity since this does not modify qualitatively the equilibrium characterization of the baseline model, as we have discussed after Proposition 1.

${ }^{19} \mathrm{By}$ assuming that the number of workers participating to committees is infinitesimal, we are ignoring the impact over the incentives at $t-1$ of rents earned by workers participating in an evaluating committee at $t$. Taking these rents into account would foster the investment in education at period $t-1$, but it would not change qualitatively any of our results.
} 
equilibrium arises (in both groups, a proportion $\frac{1+\alpha}{2}$ of workers invest). This equilibrium holds forever, $\phi_{t}^{f}=\frac{1}{2} \forall t>0$. ii) If $\gamma_{1}^{m} \leq \gamma^{*}$, a symmetric LHC equilibrium arises (in both groups, a proportion $\frac{1-\alpha}{2}$ of workers invest). This equilibrium holds forever, $\phi_{t}^{f}=\frac{1}{2} \forall t>0$. iii) Otherwise (if $\gamma_{1}^{f}<\gamma^{*}$ and $\gamma_{1}^{m}>\gamma^{*}$ ), at $t=1$, men are in the HHC equilibrium while women are in the LHC equilibrium (a proportion $\frac{1-\alpha}{2}\left(\frac{1+\alpha}{2}\right)$ of women (men) invest). This determines $\phi_{1}^{f}=\frac{1-\alpha}{2}\left(\phi_{1}^{m}=\right.$ $\left.\frac{1+\alpha}{2}\right)$ which may lead to three possible stationary equilibria for $\forall t>1$ : a) if $h\left(\frac{1-\alpha}{2}, \pi\right) \geq \gamma^{*}, a$ symmetric HHC equilibrium holds forever, and $\phi_{t}^{f}=\frac{1}{2} \forall t>1 ;$ b) if $h\left(\frac{1+\alpha}{2}, \pi\right) \leq \gamma^{*}$, a symmetric LHC equilibrium holds forever, and $\left.\phi_{t}^{f}=\frac{1}{2} \forall t>1 ; c\right)$ Otherwise $\left(h\left(\frac{1+\alpha}{2}, \pi\right)>\gamma^{*}>h\left(\frac{1-\alpha}{2}, \pi\right)\right)$, the asymmetric equilibrium holds forever, and $\phi_{t}^{f}=\frac{1-\alpha}{2} \forall t>1$.

The equilibrium path is determined by the initial condition $\phi_{0}^{f}$ and the screening complexity $\pi$. However, as shown below, there are some regions of $\pi$ for which the initial condition is not relevant for the final steady state equilibrium. For other values of $\pi$, the initial condition plays instead an important role. The next Lemma introduces three cutoffs of $\pi$ that will be useful to characterize such regions.

Lemma 3 i) Let $\pi^{*}$ be such that $\gamma^{*}=h\left(\frac{1}{2}, \pi^{*}\right)$. The first best steady state (symmetry in HHC) is feasible iff $\pi \geq \pi^{*}$. Otherwise the only symmetric equilibrium is LHC. ii) Let $\bar{\pi}^{*}$ be such that $\gamma^{*}=h\left(\frac{1-\alpha}{2}, \bar{\pi}^{*}\right)$. Independently of $\phi_{0}^{f}$, the first best steady state is always achieved if $\pi \geq \bar{\pi}^{*}$. iii) Let $\underline{\pi}^{*}$ be such that $\gamma^{*}=h\left(\frac{1+\alpha}{2}, \underline{\pi}^{*}\right)$. Independently of $\phi_{0}^{f}$, the only steady state equilibrium is the symmetric $L H C$ if $\pi<\underline{\pi}^{*}$.

Figure 1 illustrates the construction of these three cut-offs: 


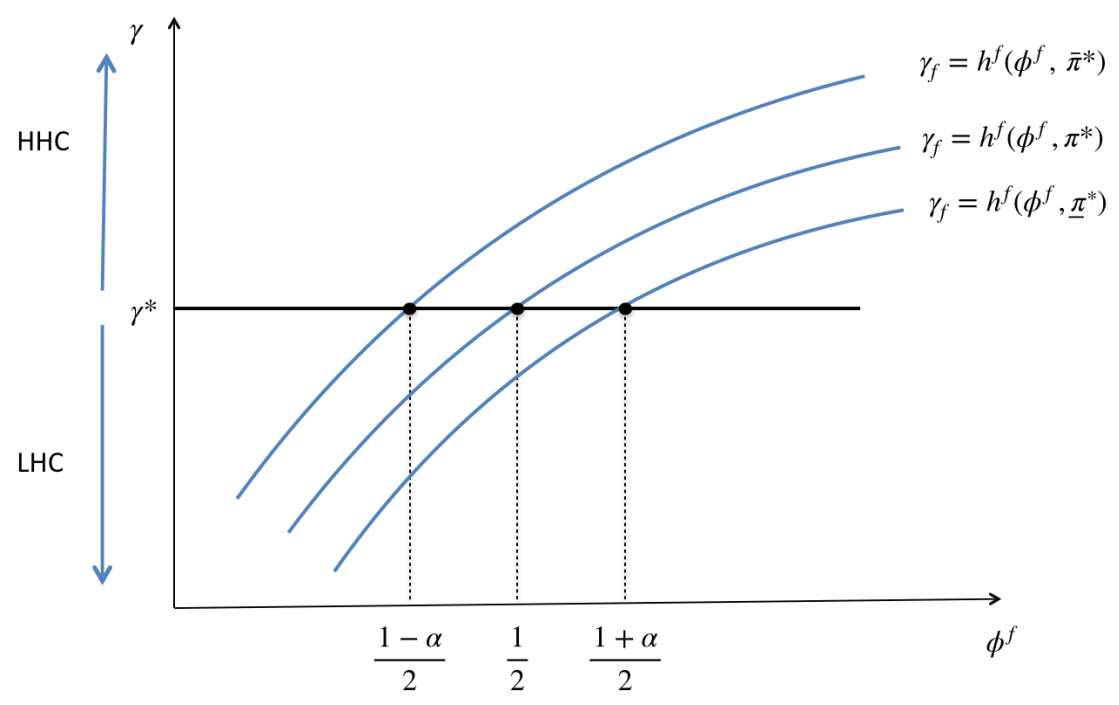

Figure 1. The cut-offs $\bar{\pi}^{*}, \pi^{*}$ and $\underline{\pi}^{*}$

Notice that $\bar{\pi}^{*} \geq \pi^{*} \geq \underline{\pi}^{*}$. Then, these cut-offs define four regions. If $\pi \geq \bar{\pi}^{*}$, the symmetric steady state HHC equilibrium will be reached no matters the initial condition $\phi_{0}^{f}$. This is because the proportion of the less represented group in the committee at $t=2, \phi_{1}^{f} \geq \frac{1-\alpha}{2}$, generates enough incentives for the strategic women to invest in human capital. If $\pi \in\left(\pi^{*}, \bar{\pi}^{*}\right)$ the initial condition is key in determining the steady state. Following Lemma 2 if the initial condition is such that the symmetric HHC is reached at $t=1$, this equilibrium will hold forever. However, if instead the asymmetric equilibrium arises at $t=1, \phi_{1}^{f}=\frac{1-\alpha}{2}$ and as $h\left(\frac{1-\alpha}{2}, \pi\right)<\gamma^{*}$, this asymmetric equilibrium in which strategic women do not invest in human capital will remain forever. Similarly, if $\pi \leq \underline{\pi}^{*}$, the symmetric steady state LHC equilibrium will be reached independently of the initial condition $\phi_{0}^{f}$. In this case, the proportion of the most represented group in the committee at $t=2$, $\phi_{1}^{m} \leq \frac{1+\alpha}{2}$, does not generate enough incentives for the strategic men to invest in human capital. Finally, if $\pi \in\left(\underline{\pi}^{*}, \pi^{*}\right)$ the initial condition becomes crucial in determining the steady state. As in the previous case, we know from Lemma 2 that if the initial condition is such that the symmetric LHC is reached at $t=1$, this equilibrium will hold forever. However, if instead the asymmetric equilibrium arises in $t=1, \phi_{1}^{m}=\frac{1+\alpha}{2}$ and as $h\left(\frac{1+\alpha}{2}, \pi\right)>\gamma^{*}$, this asymmetric equilibrium in which men invest in human capital will remain forever (remember that in this region, the symmetric 
$\mathrm{HHC}$ is not feasible).

The next Proposition states under some circumstances introducing quotas restores efficiency.

Proposition 3 i) If $\pi \in\left(\pi^{*}, \bar{\pi}^{*}\right)$ and the asymmetric steady state equilibrium arises, a "temporary" equalitarian system of quotas achieves the equalitarian first best. ii) If $\pi \in\left(\underline{\pi}^{*}, \pi^{*}\right)$ and the asymmetric steady state equilibrium arises, a "temporary" equalitarian system of quotas may reduce the total investment in human capital.

Proposition 3 shows that a system of quotas may play a role in avoiding being trapped in an inefficient equilibrium in which women are underrepresented in higher hierarchies and selection committees, hence noiser productivity signals and lower incentives to invest in human capital emerge, and thus women are less promoted and underepresented in committees.

Figure 2 illustrates with a phase dyagram in terms of $\gamma_{t}^{f}$ a situation in which quotas may restore efficiency.

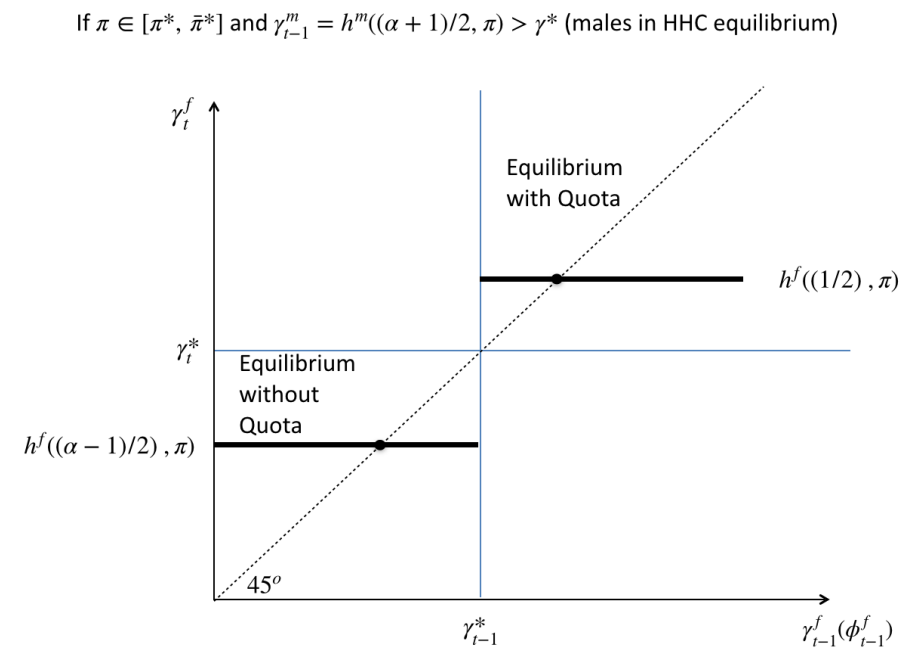

Figure 2. The role of quotas

If $\gamma_{t-1}^{f}<\gamma^{*}$, women are trapped in the LHC. As $\pi \in\left(\pi^{*}, \bar{\pi}^{*}\right)$, it is feasible to achieve the equalitarian first best. By imposing a temporary system of quotas in the committee for just one period, so that $\gamma_{t-1}^{f}>\gamma^{*}$, strategic women would have an incentive to invest in human capital, and the system would move the HHC symmetric steady state equilibrium. 
Part ii) of Proposition 3 shows that affirmative action policies may not be effective if the "context" is not favorable. The idea is that if $\pi \in\left(\underline{\pi}^{*}, \pi^{*}\right)$, that is, for high screening difficulties, asymmetric selection committees may maximize the total investment in human capital, by concentrating the effort in one of the groups and sacrificing the others. In this asymmetric equilibrium in which men are in the good equilibrium, HHC, and women in the bad one, LHC, imposing an equalitarian quota would lead the groups to levels of accuracy below the threshold $\gamma^{*}$, thereby making it possible for both groups to be in the bad equilibrium, LHC.

\section{Race versus Gender}

Consider now that the sizes of the worker groups are different: a proportion $\rho$ of red $r$ and $(1-\rho)$ of blues $b$, where $\rho<\frac{1}{2}$. Most of the previous analysis does not depend on the group size, however the dynamic analysis does. If $p_{r}$ and $p_{b}$ are the proportion of workers in each group with high productivity, the corresponding representation of each group in the evaluation committees are; $\phi_{t}^{r}=\frac{p_{r} \rho}{p_{r} \rho+p_{b}(1-\rho)}$ and $\phi_{t}^{b}=\frac{p_{b}(1-\rho)}{p_{r} \rho+p_{b}(1-\rho)}$. Then even if we are in a symmetric equilibrium in which the proportion of high productivity workers is the same in both groups $p_{r}=p_{b}$, the minority group is going to be underrepresented in the committee in the next period, since $\phi_{t}^{r}=\rho<\phi_{t}^{b}=1-\rho$. This can increase the probability that an asymmetric and inefficient equilibrium arises.

Proposition 4 The set of parameters, $\pi \in\left(\pi^{*}, \bar{\pi}^{*}\right)$, for which the asymmetric steady state equilibrium may arise and it is feasible to achieve the equalitarian first best HHC by imposing a system of quotas is larger, the smaller the size of the minority group $\rho$ is.

The intuition of the result is that the feasibility condition of the symmetric steady state HHC equlibrium $\pi \geq \bar{\pi}^{*}$ does not depend on $\rho\left(\gamma^{*}=h\left(\frac{1}{2}, \pi^{*}\right)\right)$. However, $\bar{\pi}^{*}$ in this setting is characterized by the following condition $\gamma^{*}=h\left(\frac{(1-\alpha) \rho}{(1-\alpha) \rho+(1+\alpha)(1-\rho)}, \bar{\pi}^{*}\right)$ and it is decreasing in $\rho$. Remember that $\bar{\pi}^{*}$ is the minimum level of $\pi$, such that even the minority group having the minimal representation in the committee group $\frac{(1-\alpha) \rho}{(1-\alpha) \rho+(1+\alpha)(1-\rho)}$ (strategic types of the minority 
group did not invest in human capital in the previous period) has enough incentives to invest in human capital. The lower is $\rho$, the lower is this minimal representation, and the higher is $\bar{\pi}^{*}$.

As before, if $\pi \in\left(\pi^{*}, \bar{\pi}^{*}\right)$, it is feasible to achieve the equalitarian first best HHC by imposing a system of quotas in the committee such that $\gamma^{r} \geq \gamma^{*}$. However, there is an important difference between this setting and the one analyzed before. When groups' sizes are the same, $\rho=\frac{1}{2}$, quotas may restore efficiency even if they are not permanent. In the current setting, quotas may have to be permanent for sustaining the HHC symmetric equilibrium since when both groups are in the $\mathrm{HHC}$ equilibrium, the proportion of the minority group in the committee without permanent quotas is $\rho<\frac{1}{2}$.

Let $\pi_{P}^{*}(\rho)$ be a new threshold characterized by $\gamma^{*}=h\left(\rho, \pi_{P}^{*}(\rho)\right) \cdot \pi_{P}^{*}(\rho)$ is the minimum $\pi$ such that the strategic types of minority group have enough incentives to invest in human capital, when the representation of this group in the committee is $\rho$. By construction, $\pi_{P}^{*}(\rho)$ lies in the

interior of $\left(\pi^{*}, \bar{\pi}^{*}\right)$, in the limit $\pi_{P}^{*}\left(\frac{1}{2}\right)=\pi^{*}$. If $\pi \in\left(\pi_{P}^{*}(\rho), \bar{\pi}^{*}\right)$ quotas restore efficiency even if they are non permanent, while if $\pi \in\left(\pi^{*}, \pi_{P}^{*}(\rho)\right)$ quotas should be permanent for keeping the equalitarian first best HHC equilibrium.

\section{Extensions}

\subsection{Self-confirming Stereotypes and Optimal Committee Decision Rules}

In this subsection, we consider that when taking the decision, the committee maximizes an objective function and takes into account the prior productivity distribution. In particular, the committee minimizes the following loss function

\begin{tabular}{r|cc}
$l(s, \theta)$ & $\bar{\theta}$ & $\underline{\theta}$ \\
\hline$s_{H}$ & 0 & 1 \\
$s_{L}$ & 1 & 0
\end{tabular}

When the committee takes the right decision there are no losses. Otherwise, we assume that both decision errors, type I errors (i.e to give a negative evaluation to a high productivity worker) and type II errors, (i.e to give a positive evaluation to a low productivity worker) lead to a loss 
of 1 .

We continue with the committee decision process described above. The committee either has a perfect evidence over the productivity of the worker (in that case, the decision is still trivial) or it has no information at all over the productivity of the worker. In this later case, instead of using a lottery as before, the committee takes the optimal decision given the prior. If the committee has no evidence on worker's productivity, the optimal decision is $s_{H}$, if the prior of $\bar{\theta}$ is higher than $\frac{1}{2}$, and $s_{L}$ if the prior is lower than $\frac{1}{2}$.

Now, we move to determine the priors. Notice that the decision of the committee depends on priors but also priors have to be fully consistent with the equilibrium actions of the workers, that, at the same time, depend on the information structure and the decision of the committee. In other words, we have to introduce the committee behaviour into the characterization of the Perfect Bayesian Nash Equilibrium of the game.

We start by assuming HHC or LHC equilibrium. The equilibrium path determines the priors and the optimal committee decisions (information structure). Finally, we have to check that the initial hypothesis over the equilibrium is in fact correct.

6.1.1 The High Human Capital (HHC) Equilibrium As we assume to be in the HHC equilibrium, $\operatorname{Pr}(\bar{\theta})=\frac{1+\alpha}{2}>\frac{1}{2}$. Given this prior, the committee's decision over a worker of group $j$ is as follows: i) with probability $\Gamma=1-(1-\pi \sigma)^{\phi^{j} N}(1-\pi)^{\left(1-\phi^{j}\right) N}$, the productivity is observed by at least one member of the committee and $s \in\left\{s_{H}, s_{L}\right\}$ is chosen in order to match the worker's productivity $\theta \in\{\bar{\theta}, \underline{\theta}\}$; ii) with probability $1-\Gamma$, the productivity is not observed and $s_{H}$ is chosen given $\operatorname{Pr}(\bar{\theta})=\frac{1+\alpha}{2}>\frac{1}{2}$.

The committee's decisions is characterized by the following information structure,

\begin{tabular}{r|cc}
$\operatorname{Pr}(s \mid \theta)$ & $\bar{\theta}$ & $\underline{\theta}$ \\
\hline$s_{H}$ & 1 & $1-\gamma$ \\
$s_{L}$ & 0 & $\gamma$
\end{tabular}

where $\gamma=h^{j}\left(\phi^{j}, \pi\right)=\Gamma$. If the worker has high productivity, the signal is always positive (either the productivity is observed or it is not, but $s_{H}$ is chosen since $\bar{\theta}$ is more likely and the 
loss function is symmetric). If the worker has low productivity, the signal is negative when the productivity is observed (with probability $\Gamma$ ), and the signal is positive otherwise.

Now, we have to check if strategic workers prefer to invest in human capital under this information structure. Following the same steps of the characterization of the equilibrium in the main model, the expected salaries given the productivity are:

$$
\begin{aligned}
& W_{\bar{\theta}}\left(\gamma, \frac{1+\alpha}{2}\right)=w\left(s_{H}\right) \\
& W_{\underline{\theta}}\left(\gamma, \frac{1+\alpha}{2}\right)=\gamma w\left(s_{L}\right)+(1-\gamma) w\left(s_{H}\right)
\end{aligned}
$$

The incentives to invest in human capital are driven by the incremental expected pay-off between high and low productivity being larger than the investment cost

$$
W_{\bar{\theta}}\left(\gamma, \frac{1+\alpha}{2}\right)-W_{\underline{\theta}}\left(\gamma, \frac{1+\alpha}{2}\right) \geq \widehat{c}
$$

In our case, $W_{\bar{\theta}}\left(\gamma, \frac{1+\alpha}{2}\right)-W_{\underline{\theta}}\left(\gamma, \frac{1+\alpha}{2}\right)=\gamma \bar{\theta}\left(\operatorname{Pr}\left(\bar{\theta} \mid s_{H}\right)-\operatorname{Pr}\left(\bar{\theta} \mid s_{L}\right)\right)$ but $\operatorname{Pr}\left(\bar{\theta} \mid s_{L}\right)=0$. Therefore, the $\mathrm{HHC}$ equilibrium arises if

$$
\gamma \bar{\theta} \operatorname{Pr}\left(\bar{\theta} \mid s_{H}\right)=\frac{\gamma \bar{\theta}(1+\alpha)}{2-\gamma(1-\alpha)} \geq \widehat{c}
$$

As the left hand side is increasing in $\gamma$, we can rewrite this incentive compatibility condition as follows:

$$
\gamma \geq \underline{\gamma}=\frac{2}{(1+\alpha) \frac{\bar{\theta}}{\bar{c}}+(1-\alpha)}
$$

\subsubsection{The Low Human Capital (LHC) Equilibrium Following the same arguments, we} characterize the conditions for the LHC equilibrium. In this case $\operatorname{Pr}(\bar{\theta})=\frac{1-\alpha}{2}<\frac{1}{2}$. As in the previous case, with probability $\Gamma=1-(1-\pi \sigma)^{\phi^{j} N}(1-\pi)^{\left(1-\phi^{j}\right) N}$, the productivity is observed and the decision is trivial. With probability $1-\Gamma$, the productivity is not observed and $s_{L}$ is chosen given $\operatorname{Pr}(\bar{\theta})=\frac{1-\alpha}{2}<\frac{1}{2}$. The information structure that summarized the group decision is the following,

\begin{tabular}{r|cc}
$\operatorname{Pr}(s \mid \theta)$ & $\bar{\theta}$ & $\underline{\theta}$ \\
\hline$s_{H}$ & $\gamma$ & 0 \\
$s_{L}$ & $1-\gamma$ & 1
\end{tabular}


where $\gamma=h^{j}\left(\phi^{j}, \pi\right)=\Gamma$. Contrary to the previous case, if the worker has low productivity, the signal is always negative (either the productivity is observed or it does not, but $s_{L}$ is chosen since $\underline{\theta}$ is more likely and the loss function is symmetric). If the worker has high productivity, the signal is positive when the productivity is observed (with probability $\Gamma$ ), and negative otherwise.

We now have to check if strategic workers prefer not to invest in human capital under this information structure. We start by computing the expected salaries given the productivity:

$$
\begin{aligned}
& W_{\bar{\theta}}\left(\gamma, \frac{1-\alpha}{2}\right)=\gamma w\left(s_{H}\right)+(1-\gamma) w\left(s_{L}\right) \\
& W_{\underline{\theta}}\left(\gamma, \frac{1-\alpha}{2}\right)=w\left(s_{L}\right)
\end{aligned}
$$

The incentive compatibility conditions in the LHC is that the incremental expected pay-off between high and low productivity is lower than the investment cost

$$
W_{\bar{\theta}}\left(\gamma, \frac{1-\alpha}{2}\right)-W_{\underline{\theta}}\left(\gamma, \frac{1-\alpha}{2}\right) \leq \widehat{c}
$$

In this case, $W_{\bar{\theta}}(\gamma, p)-W_{\underline{\theta}}(\gamma, p)=\gamma \bar{\theta}\left(\operatorname{Pr}\left(\bar{\theta} \mid s_{H}\right)-\operatorname{Pr}\left(\bar{\theta} \mid s_{L}\right)\right)$ but $\operatorname{Pr}\left(\bar{\theta} \mid s_{H}\right)=1$, then the LHC equilibrium arises if

$$
\left.\gamma \bar{\theta}\left(1-\operatorname{Pr}\left(\bar{\theta} \mid s_{L}\right)\right)=\gamma \bar{\theta} \operatorname{Pr}\left(\underline{\theta} \mid s_{L}\right)\right)=\frac{\gamma \bar{\theta}(1+\alpha)}{2-\gamma(1-\alpha)} \leq \widehat{c}
$$

We can rewrite this incentive compatibility condition is terms of $\gamma$ :

$$
\gamma \leq \bar{\gamma}=\frac{2}{(1+\alpha) \frac{\bar{\theta}}{\hat{c}}+(1-\alpha)}
$$

6.1.3 The Equilibria under the Optimal Decision Rule. Surprisingly, even though the optimal decision rule leads to different information structures in the HHC and LLC equilibria, both equilibria are characterized by a single cut-off $\underline{\gamma}=\bar{\gamma}=\gamma^{* *}$ where $\gamma^{* *}=\frac{2}{(1+\alpha) \frac{\bar{\theta}}{\bar{c}}+(1-\alpha)}$ and there is no multiplicity of equilibria.

Proposition 5 Under the optimal decision rule, when the level of accuracy $\gamma$ is lower than $\gamma^{* *}$, the only equilibrium is the $L H C$, whereas, when the level of accuracy is higher than $\gamma^{* *}$, the only equilibrium is the $\mathrm{HHC}$. 
If we embody the model under the optimal decision rule into our dynamic setting, we obtain the same pattern than before. An inefficient asymmetric equilibrium may arise, in which a proportion of $\frac{1-\alpha}{2}\left(\frac{1+\alpha}{2}\right)$ of females (males) invest. When both groups are in different equilibria, they face different evaluation policies. No news in case of men leads to a positive evaluation, $s_{H}$, while no news in case of women leads to a negative evaluation, $s_{L}$. This result goes in line with discrimination for "self-confirming stereotypes" of Arrow (1973), Foster and Vohra (1992), Coate and Loury (1993) and Moro and Norman (2004). ${ }^{20}$

Proposition 6 The HHC arises for the larger set of parameters under the optimal decision rule, i.e $\gamma^{* *} \leq \gamma^{*}$.

The optimal decision rule leads to better incentives to invest in human capital.

\subsection{Committee Decision and Voting.}

We now consider that the aggregation of information within the committee and the decision are done through a voting system. Each committee member votes, $r_{i} \in\{0,1\}$, and the candidate obtains a positive evaluation if the number of positive votes $R=\sum_{i=1}^{N} r_{i}$, is larger than a common threshold $\bar{R}$.

$$
s= \begin{cases}s_{H} & \text { if } R=\sum_{i=1}^{N} r_{i}>\bar{R} \\ s_{L} & \text { otherwise. }\end{cases}
$$

The voting behaviour is determined by the information hold by committees' members but it may also be affected by strategic behaviour, or bias towards some group. We set up the homoaccuracy assumption in this setting as follows. When a woman is evaluated, the probability that a female member of the committee votes "right" is higher than a male member votes "right": $\operatorname{Pr}\left\{r=1 \mid \theta_{f}=\bar{\theta}\right\}_{f} \geq \operatorname{Pr}\left\{r=1 \mid \theta_{f}=\bar{\theta}\right\}_{m}$ and $\operatorname{Pr}\left\{r=1 \mid \theta_{f}=\underline{\theta}\right\}_{f} \leq \operatorname{Pr}\left\{r=1 \mid \theta_{f}=\underline{\theta}\right\}_{m}$. For tractabilty, we also assume that the probability of voting right accross committees' members is symmetric, it only depends on their match with the candidate's group and the productivity of the

\footnotetext{
${ }^{20}$ Also this result goes in line with the views of Sheryl Kara (Chief operating officer of Facebook) "Women have to prove themselves to a far greater extent than men do... a 2011 McKinsey report noted that men are promoted based on potential, while women are promoted based on past accomplishments."
} 
worker under evaluation.

Given a committee compostion $\phi^{f}$, we can treat the number of positive votes $R$ as a random variable, and we denote as $\operatorname{Pr}(R \mid \bar{\theta})$ the probability of receiving $R$ positive votes. The next lemma states an important relationship between the composition of the committee and the probability distribution of $R$.

Proposition 7 If a female is evaluated and $\phi^{f}>\phi^{f}$ then $\sum_{R=1}^{n} \operatorname{Pr}(R \mid \bar{\theta})_{\phi^{f}} \leq \sum_{R=1}^{n} \operatorname{Pr}(R \mid \bar{\theta})_{\phi^{f}}$, for all $n \leq N$ and $\sum_{R=1}^{n} \operatorname{Pr}(R \mid \underline{\theta})_{\phi^{f}} \geq \sum_{R=1}^{n} \operatorname{Pr}(R \mid \underline{\theta})_{\phi^{f}}$, for all $n \leq N$.

A direct implication of Proposition 7 (ordering the votes distribution according to first order stochastic dominance) is that, if a high (low) productivity woman is evaluated, the larger the proportion of women in the committee, the higher (lower) is, in expectation, the number of positive votes.

We do not make any assumption on how the threshold $\bar{R}$ is chosen, since our results do not depend on it. Given the distribution of votes and the threshold $\bar{R}$, we can compute the expected outcome of the evaluation process. Suppose that a female worker is evaluated for a committee with a proportion $\phi^{f}$ of female members. The expected outcome of this evaluation process is summarized by the following information structure:

\begin{tabular}{r|cc}
$\operatorname{Pr}(s \mid \theta)$ & $\bar{\theta}$ & $\underline{\theta}$ \\
\hline$s_{H}$ & $\gamma_{\bar{\theta}}^{f}\left(\phi^{f}\right)$ & $1-\gamma_{\hat{\theta}}^{f}\left(\phi^{f}\right)$ \\
$s_{L}$ & $1-\gamma_{\bar{\theta}}^{f}\left(\phi^{f}\right)$ & $\gamma_{\underline{\theta}}^{f}\left(\phi^{f}\right)$
\end{tabular}

where $\gamma_{\bar{\theta}}^{f}\left(\phi^{f}\right)=1-\sum_{R=0}^{\bar{R}} \operatorname{Pr}(R \mid \bar{\theta})_{\phi^{f}}$ (the probability that a high productivity female worker obtains at least $\bar{R}$ positive votes) and $\gamma_{\underline{\theta}}^{f}\left(\phi^{f}\right)=\sum_{R=0}^{R} \operatorname{Pr}(R \mid \underline{\theta})_{\phi^{f}}$ (the probability that a low productivity female worker obtains less than $\bar{R}$ positive votes).

An alternative way to present the expected outcome of the committee decision process is to compute the probability of decision errors. Next Corollary of Proposition 7 states how these decision errors depend on the composition of the committee. 
Corollary 8 Let $\bar{R}$ be the committee threshold, if a woman is evaluated and $\phi^{f}>\phi^{f^{\prime}}$, then a committee with a proportion $\phi^{f}$ of women is making less decisions errors than a committee with a proportion $\phi^{f^{\prime}}$ of women: i) Lower Type I errors $1-\gamma_{\bar{\theta}}^{f}\left(\phi^{f}\right)=\sum_{R=0}^{\bar{R}} \operatorname{Pr}(R \mid \bar{\theta})_{\phi^{f}} \leq 1-\gamma_{\bar{\theta}}^{f}\left(\phi^{f^{\prime}}\right)=$ $\sum_{i=0}^{\bar{R}} \operatorname{Pr}(R \mid \bar{\theta})_{\phi_{f^{\prime}}}$ and ii) Lower Type II errors $1-\gamma_{\underline{\theta}}^{f}\left(\phi^{f}\right)=1-\sum_{R=0}^{\bar{R}} \operatorname{Pr}(R \mid \underline{\theta})_{\phi^{f}}<1-\gamma_{\underline{\theta}}^{f}\left(\phi^{f^{\prime}}\right)=$ $1-\sum_{i=0}^{\bar{R}} \operatorname{Pr}(R \mid \underline{\theta})_{\phi^{f^{\prime}}}$.

We are not going to fully characterize the equilibrium, since it would require additional assumptions and constraints. We are going instead to focus on the incentives to invest in human capital of female and male workers when women are underepresented in the committee.

In order to do so, we start by computing the expected payoffs of workers with the above asymmetric information structure and with a prior belief $\operatorname{Pr}(\bar{\theta})=p$. In this case

$$
\begin{aligned}
& W_{\bar{\theta}}\left(\gamma_{\bar{\theta}}, \gamma_{\underline{\theta}}, p\right)=\gamma_{\bar{\theta}} w\left(s_{H}\right)+\left(1-\gamma_{\bar{\theta}}\right) w\left(s_{L}\right) \\
& W_{\underline{\theta}}\left(\gamma_{\bar{\theta}}, \gamma_{\underline{\theta}}, p\right)=\gamma_{\underline{\theta}} w\left(s_{L}\right)+\left(1-\gamma_{\underline{\theta}}\right) w\left(s_{H}\right)
\end{aligned}
$$

Similarly to the main model, $w\left(s_{H}\right)=\bar{\theta}\left(\operatorname{Pr}\left(\bar{\theta} \mid s_{H}\right), w\left(s_{L}\right)=\bar{\theta} \operatorname{Pr}\left(\bar{\theta} \mid s_{L}\right)\right.$ and the incentives to invest in human capital are driven by the incremental expected pay-off between high and low productivity.

$$
W_{\bar{\theta}}\left(\gamma_{\bar{\theta}}, \gamma_{\underline{\theta}}, p\right)-W_{\underline{\theta}}\left(\gamma_{\bar{\theta}}, \gamma_{\underline{\theta}}, p\right)=\left(\gamma_{\bar{\theta}}+\gamma_{\underline{\theta}}-1\right) \bar{\theta}\left(\operatorname{Pr}\left(\bar{\theta} \mid s_{H}\right)-\operatorname{Pr}\left(\bar{\theta} \mid s_{L}\right)\right)
$$

Lemma 4 Incentives to invest in human capital, $W_{\bar{\theta}}\left(\gamma_{\bar{\theta}}, \gamma_{\underline{\theta}}, p\right)-W_{\underline{\theta}}\left(\gamma_{\bar{\theta}}, \gamma_{\underline{\theta}}, p\right)$, are increasing in $\gamma_{\bar{\theta}}$ and $\gamma_{\underline{\underline{\theta}}}$.

This lemma follows the same logic of Lemma 1 of the main model: higher accuracy increases the payoffs of investing in human capital and decreases payoffs of not doing it.

From Propostion 7, if $\phi^{f}<\frac{1}{2}, \gamma_{\bar{\theta}}^{m}\left(\phi^{m}\right) \geq \gamma_{\bar{\theta}}^{f}\left(\phi^{f}\right)$ and $\gamma_{\underline{\theta}}^{m}\left(\phi^{f}\right) \geq \gamma_{\underline{\theta}}^{f}\left(\phi^{f}\right)$ then men have more incentives to invest in human capital than women also when the committee uses a voting system to take the decision. 


\subsection{A Dynamic Model with Continuous Distribution of Types}

We modify our dynamic setting by considering a continuous distribution of workers' types. As in the main model, every stage of the dynamic game is identical to the static model. A new cohort of workers of measure one is born every period. Every cohort is composed by two identical ex-ante groups $m$ and group $f$ (i.e. with the same size and the same continuous distribution of talent cost $G()$.$) . Regarding the distribution of talent, we assume that the fixed cost of investing in$ human capital, $c \geq 0$ is independently distributed according to a continuous uniform distribution function over $[0,1], c \sim G()=.U[0,1]$.

All workers learn their types $c$, and take their decisions over investing or not in human capital. Beside the new distribution of types, most of the workers work for only one period before retirement and they face the same trade-offs as we have analyzed before. As before, the dynamic link is that an infinitesimal but representative proportion of educated workers of both groups is promoted to the evaluation committee in the second period.

$$
\gamma_{t}^{j}=h\left(\phi_{t-1}^{j}, \pi\right) \forall t
$$

where $\phi_{t-1}^{j}$ is the proportion of group $j$ among the group of workers that have invested in human capital at $t-1$.

We first characterized the static perfect bayesian equilibrium for a continuous distribution of fixed costs in a static setting. In order to do that, we will focus in a simple asymmetric information structure that is analyzed in the appendix, $\operatorname{Pr}\left(s_{H} \mid \bar{\theta}\right)=1$ and $\operatorname{Pr}\left(s_{L} \mid \underline{\theta}\right)=\frac{1+\gamma}{2}$, where $\gamma$ represents the accuracy of the signal. The advantage of this information structure is that it simplifies the analysis, since a bad realization is fully revealing, $\operatorname{Pr}\left(\bar{\theta} \mid s_{L}\right)=0$.

In the appendix, we characterize the static bayesian equilibrium with this information structure and discrete types. The main insight of the analysis is that there exists multiplicity of equilibria. However, in the continuous case, there is only one equilibrium characterized by a unique marginal type $\widetilde{c}$. In this equilibrium, the marginal type is indifferent between investing or not in human capital, where higher types (lower types) prefer not to invest (to invest). Using this feature of the 
equilibrium, we characterize the marginal type, $\widetilde{c}$, as follows:

$$
W_{\bar{\theta}}(\gamma, p)-W_{\underline{\theta}}(\gamma, p)=\widetilde{c}
$$

The computation of the expected salary is analogous to the main model, that is $W_{\bar{\theta}}(\gamma, p)=$ $w\left(s_{H}\right)$ and $W_{\bar{\theta}}(\gamma, p)=(1-\gamma) w\left(s_{H}\right)$, where the expected wage is equal to the expected productivity of the worker $w\left(s_{H}\right)=\bar{\theta} \operatorname{Pr}\left(\bar{\theta} \mid s_{H}\right)$. We can rewrite the equation (5) as follows:

$$
\bar{\theta} \operatorname{Pr}\left(\bar{\theta} \mid s_{H}\right)-\left(\frac{1-\gamma}{2}\right) \bar{\theta} \operatorname{Pr}\left(\bar{\theta} \mid s_{H}\right)=\left(\frac{1+\gamma}{2}\right) \bar{\theta} \operatorname{Pr}\left(\bar{\theta} \mid s_{H}\right)=\widetilde{c}
$$

All types with $c$ lower than $\widetilde{c}$ invest in human capital, and those with higher costs do not invest. Then, the prior is equal to the proportion of educated workers in the population $p=G(\widetilde{c})=\widetilde{c}$. Using this and the bayes rule, we obtain

$$
\operatorname{Pr}\left(\bar{\theta} \mid s_{H}\right)=\frac{G(\widetilde{c})}{G(\widetilde{c})+\left(\frac{1-\gamma}{2}\right)(1-G(\widetilde{c})}
$$

Plugging this expression into equation (6) and simplifying we obtain:

$$
\frac{1-\gamma}{1+\gamma}=\frac{G(\widetilde{c})}{\widetilde{c}}(\bar{\theta}-\widetilde{c})
$$

As $c$ is uniformly distributed on $[0,1]$, the indifferent type $\widetilde{c}$ is also $G(\widetilde{c})$. Using this, we can explicitly define the indifferent type, $\widetilde{c}$, as a function of the accuracy level $\gamma$.

$$
\widetilde{c}=\bar{\theta}+1-\frac{2}{1+\gamma}
$$

Notice that the marginal type (the proportion of workers investing in human capital) is increasing with the accuracy of the productivity signal $\gamma$. If $\gamma=1$ (i.e. perfect information) the worker invests in skills if $c \leq \bar{\theta}$.

We move to analyze the statistical discrimination problem in this dynamic and continuous setting. As before, our key variable is the proportion of women among the educated workers in $t, \phi_{t}^{f}$ that will be also the proportion of women in the evaluation committee in $t+1: \phi_{t}^{f}=\frac{\widetilde{c}_{t}^{f}}{\widetilde{c}_{t}^{m}+\widetilde{c}_{t}^{f}}$ and $\phi_{t}^{m}=\frac{\widetilde{c}_{t}^{m}}{\widetilde{c}_{t}^{m}+\widetilde{c}_{t}^{f}}$.

To save notation, $\bar{\theta}=1$. Then, the marginal types are $\widetilde{c}_{t}^{f}=\frac{2 \gamma_{t}^{f}}{1+\gamma_{t}^{f}}$ and $\widetilde{c}_{t}^{m}=\frac{2 \gamma_{t}^{m}}{1+\gamma_{t}^{m}}$. Using these expressions and the accuracy functions $\gamma_{t}^{f}=h\left(\phi_{t-1}^{f}, \pi\right)$ and $\gamma_{t}^{m}=h\left(1-\phi_{t-1}^{f}, \pi\right)$, we can 
derive the dynamic equation between the proportion of women in the evaluation committee (state variable) in periods $t-1$ and $t$.

$$
\phi_{t}^{f}=\frac{1}{1+\frac{1+h\left(\phi_{t-1}^{f}, \pi\right)}{h\left(\phi_{t-1}^{f}, \pi\right)} \frac{h\left(1-\phi_{t-1}^{f}, \pi\right)}{1+h\left(1-\phi_{t-1}^{f}, \pi\right)}}
$$

Next proposition states that this dynamic equation (8) has three steady state equilibria.

Proposition 9 There exist three decentralized equilibria, $\phi_{t}^{f}=\phi_{t-1}^{f}=\phi_{E E}^{f}$;i) $\phi_{E E}^{f}=1 / 2$; ii) $\phi_{E E}^{f}=1$; and iii) $\phi_{E E}^{f}=0$.

The equalitarian allocation is always a decentralized equilibrium but the optimality (efficiency) and stability of such equilibrium depends on $h(\phi, \pi)$.

In the discrete model, maximizing total welfare is equivalent to maximize the total proportion of educated workers (since investment in human capital was assumed to be efficient for strategic types). In the present setting, what also matters is who invests in human capital. Welfare maximization requires that workers with the lower cost of investing in human capital invest, independently of the group they belong to. In particular, total welfare depends on the proportion of educated workers in both groups $\widetilde{c}^{j}$ (since we have normalized the productivity of educated workers to 1) and their cost of investment in human capital $\int_{0}^{\widetilde{c}^{j}} c^{j} g\left(c^{j}\right) d c^{j}$. Then, the efficient $\phi^{f *}$ in the steady state is characterized by the solution of the following maximization problem:

$$
\begin{aligned}
\phi^{f *} \in & \arg \max \left\{\left[\widetilde{c}^{f}-\int_{0}^{\widetilde{c}^{f}} c^{f} g\left(c^{f}\right) d c^{f}\right]+\right. \\
& {\left.\left[\widetilde{c}^{m}-\int_{0}^{\widetilde{c}^{m}} c^{m} g\left(c^{m}\right) d c^{m}\right]\right\} } \\
\text { s.t. } \widetilde{c}^{f}= & \frac{2 h\left(\phi^{f}, \pi\right)}{1+h\left(\phi^{f}, \pi\right)} \text { and } \widetilde{c}^{m}=\frac{2 h\left(1-\phi^{f}, \pi\right)}{1+h\left(1-\phi^{f}, \pi\right)}
\end{aligned}
$$

Next proposition provides a sufficient condition for the equalitarian composition of the selection committee, $\phi^{f *}=\phi^{m *}=\frac{1}{2}$, to be efficient when, as it is in our case, the talent is equally distributed among groups.

Proposition 10 If $h(\phi, \pi)$ is concave with respect to $\phi$, the efficient solution is $\phi^{f *}=\phi^{m *}=\frac{1}{2}$. 
Proposition 10 relies on two features of the problem. i) For a given number of educated workers, an equalitarian distribution among both groups minimizes the total workers' investment in human capital. ii) When the accuracy function $h(\phi, \pi)$ is concave, an equalitarian composition of the evaluation committee maximizes the total number of educated workers in the population. On the contrary, if $h(\phi, \pi)$ is convex, a non equalitarian composition of the selection committee may maximize the total number of educated workers. This is because the marginal impact of increasing the representation of one group in the evaluation committee over the accuracy function is increasing in the current proportions of members of this group in the evaluation committee.

We are interested in the stability of the equalitarian equilibrium. As the dynamic equation $\phi_{t}^{f}=f\left(\phi_{t-1}^{f}, \pi\right)$ is continuous and differentiable, the condition for the equalitarian equilibrium being stable is that the slope of $f$ is lower than 1 when $\phi_{t-1}^{f}=\frac{1}{2}$. This condition translates into the following one:

$$
\left.\frac{\partial f\left(\phi_{t-1}^{f}, \pi\right)}{\partial \phi_{t-1}^{f}}\right|_{\phi_{t-1}^{f}=\frac{1}{2}}=\frac{h^{\prime}\left(\frac{1}{2}, \pi\right)}{2 h\left(\frac{1}{2}, \pi\right)\left(1+h\left(\frac{1}{2}, \pi\right)\right)}<1
$$

Proposition 11 If $h(\phi, \pi)$ is concave with respect to $\phi$ the equalitarian equilibrium $\phi^{f *}=\phi^{m *}=$ $\frac{1}{2}$ is stable.

Contrary to the previous literature (Foster and Vohra (1992) and Coate and Loury (1993)), in our setting there exists a negative externality between population groups. Increasing the representation (accuracy) of one group, reduces the representation (accuracy) of the other group. Intuitively, concavity of the accuracy functions implies that if we increase the representation of the minority groups, the gains (and incentives) of this group compensates the losses of the mayoritarian group. However, quotas may still play a role, not only to accelerate the transition to the efficient equalitarian equilibrium, but also to restore efficiency outside of the concave case.

Now, we take an arbitrary accuracy function $h(\phi, \pi)=\phi^{\frac{1}{\pi}}$. This function is concave when $\pi \in(1, \infty)$, and then for this range of parameters the equalitarian allocation $\phi^{f *}=\phi^{m *}=\frac{1}{2}$ is efficient. However, concavity of $h(\phi, \pi)$ is a sufficient but not necessary condition for the 
efficiency of the equalitarian equilibrium. In fact, in this particular example, $\phi^{f *}=\phi^{m *}=\frac{1}{2}$ is efficient beyond the concave region, if $\pi>0.4$. Concavity is also not a necessary condition for stability, but in this example, stability of the equalitarian equilibrium requires a stronger condition, $\pi>0.72$. Figure 3 shows the system dynamic equation when $\pi$ is lower o higher than 0.72 , and the equalitarian equilibrium is or is not stable.the equalitarian equilibrium is or is not stable.
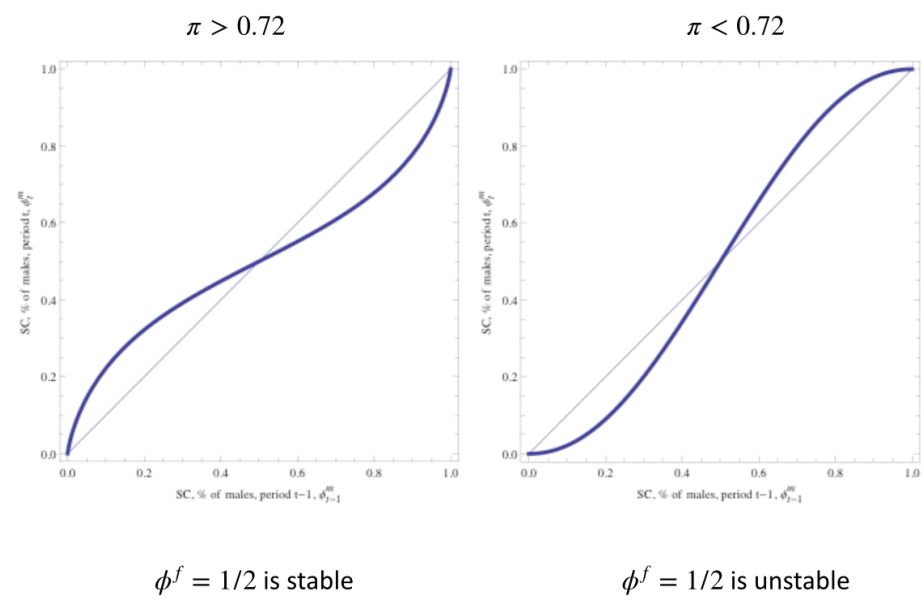

Figure 3. Stability and Concavity.

Therefore, if $h(\phi, \pi)=\phi^{\frac{1}{\pi}}$ and $\pi \in(0.4,0.72)$, the equalitarian equilibrium is efficient but unstable. In that case, imposing an equalitarian and (permanent) system of quotas may increase total welfare. Notice that restoring efficiency in this dynamic setting with continuous distribution of investment costs has important implications in the allocation of talent. Quotas not only will provide incentives to invest in human capital to talented women, but also these talented women will replace less talented, "mediocre", men (Besley et al (2017)).

\subsection{A Model with Continuous Effort.}

In this extension, we analyze a pure moral hazard setting. We remove the heterogeneity of the workers and we introduce a continous level of effort and uncertainty. A worker decides how 
much to invest in human capital $e \geq 0$. Investing entails a cost $c(e)$, where $c(e)$ is increasing and convex. The mapping between investment in human capital and productivity is not deterministic. If a worker invests $e$, this leads to high productivity $\bar{\theta}$ with probability $e$, whereas with the complementary probability the worker will have low productivity $\underline{\theta}$.

As before, workers' productivity is imperfectly observed, and future payoffs are determined by workers' productivity and the previous simple information structure $\operatorname{Pr}\left(s_{H} \mid \bar{\theta}\right)=1$ and $\operatorname{Pr}\left(s_{L} \mid \underline{\theta}\right)=\frac{1+\gamma}{2}$.

We solve the game backwards. Thus, we start by determining the expected salary of the workers. We know that under this information structure, a negative signal is fully revealing $\operatorname{Pr}\left(\underline{\theta} \mid s_{L}\right)=0$, and $w\left(s_{L}\right)=0$. To determinine the expected salary when the worker receives a positive evaluation $w\left(s_{H}\right)=\bar{\theta} \operatorname{Pr}\left(\bar{\theta} \mid s_{H}\right)$, we start from determining the priors.

Workers investing $e$ will be high productivity workers with probability $\operatorname{Pr}(\bar{\theta})=e$, and low productivity workers with probability $\operatorname{Pr}(\underline{\theta})=1-e$. Then, when workers receive a positive evaluation and the expected investment in human capital of $e$, the expected productivity $\operatorname{Pr}\left(\bar{\theta} \mid s_{H}\right)$ according to the bayes rule is:

$$
\operatorname{Pr}\left(\bar{\theta} \mid s_{H}\right)=\frac{\operatorname{Pr}\left(s_{H} \mid \bar{\theta}\right) \operatorname{Pr}(\bar{\theta})}{\operatorname{Pr}\left(s_{H} \mid \bar{\theta}\right) \operatorname{Pr}(\bar{\theta})+\operatorname{Pr}\left(s_{H} \mid \underline{\theta}\right) \operatorname{Pr}(\underline{\theta})}=\frac{e}{e+(1-e)\left(\frac{1-\gamma}{2}\right)}
$$

where $\operatorname{Pr}\left(\bar{\theta} \mid s_{H}\right)$ and $w\left(s_{H}\right)=\bar{\theta} \operatorname{Pr}\left(\bar{\theta} \mid s_{H}\right)$ are increasing in $e$ and $\gamma \in[0,1]$.

Given that the optimal (equilibrium) effort is:

$$
e^{*} \in \arg \max \left\{\left[e+(1-e)\left(\frac{1-\gamma}{2}\right)\right] \bar{\theta} \operatorname{Pr}\left(\bar{\theta} \mid s_{H}\right)-c(e)\right\}
$$

Where $e+(1-e)\left(\frac{1-\gamma}{2}\right) e=\frac{1-\gamma}{2}+\left(\frac{1+\gamma}{2}\right) e$ is the probability of $s_{H}$ realization. When the worker decides her optimal investment decision, she should take as given the expected level of effort $e$ in $\operatorname{Pr}\left(\bar{\theta} \mid s_{H}\right)$. Then, her incentives are given by marginal gains of increasing the effort $\left(\frac{1+\gamma}{2}\right) \bar{\theta} \operatorname{Pr}\left(\bar{\theta} \mid s_{H}\right) \bar{\theta}$ and its marginal cost $c^{\prime}(e)$. Notice that the marginal gains $\left(\frac{1+\gamma}{2}\right) \bar{\theta} \operatorname{Pr}\left(\bar{\theta} \mid s_{H}\right) \bar{\theta}$ of effort are increasing in $\gamma$. Then, the higher is the expected accuracy, the higher will be the incentives to invest in human capital. 
For obtaining the Perfect Bayesian Equilibrium, the optimal investment effort by the worker given the incentives should coincide with the expected level of effort.

$$
\frac{1+\gamma}{2} \bar{\theta} \frac{e^{*}}{e^{*}+\left(1-e^{*}\right)\left(\frac{1-\gamma}{2}\right)}-c^{\prime}\left(e^{*}\right)=0
$$

If we consider a quadratic cost function $c(e)=\frac{e^{2}}{2}$, the equilibrium level of effort has a closed form solution

$$
e^{*}(\gamma)=\bar{\theta}+1-\frac{2}{1+\gamma}
$$

This is also the cut-off of the continuous distribution model (equation (7)) and therefore, we could derive similar implications.

\section{Conclusions}

This paper introduces a statistical discrimination mode,l in which the evaluation of workers' productivity is done by a committee. Due to the "homo-accuracy" bias, the group that is most represented in the evaluation committee generates more accurate signals, and consequently has a greater incentive to invest in human capital. In this setting, if the evaluation committee is initially not equalitarian, this could translate into a persistent discriminatory trap, where the less represented group in the evaluation committees has less incentives to invest and is then less productive. This asymmetric equilibrium is inefficient, since there is a waste of talent in the discriminated group. Quotas imposed on evaluation committees are shown to be an effective mechanism to restore efficiency.

Our paper provides a new rationale to support affirmative action policies at the top level positions in organizations. Matsa and Miller (2011) find positive gender spillovers between the board of directors (that appoint and oversee the company's managers) in organizations and the promotions of women to top positions. This paper shows that when women's share of board seats increases, women's share of top executive positions also increases. Consistently with our theoretical results, the authors suggest as possible explanation of this gender spillover that "women individuals are better able to interpret noisy signals about ability for members of their own sex". 
As we claim that quotas may generate efficiency gains, our result may also justify self regulation policies for promoting diversity in top positions that we observe in many organizations. However, we also show that affirmative action policies may not be effective if the "context" is not favorable. This could explain that other firms are reluctant to promote diversity and prefer to be specialized in one group of workers. Athey et al (2000) in a mentoring framework also shows that specialization may be optimal for some firms.

Our model is the first theoretical analysis of the role of committees in statistical discrimination, raising new theoretical and empirical research questions. On the theoretical side, we have focused on a frictionless committee deliberation process with common interests. By doing so, we have ignored the analysis of the strategic behaviour among committee members that arises when it is costly to acquire or reveal information, or if committee members are limited to cast a vote. The so call "homo-accuracy" assumption is the driving force of our results. While, we have provided some empirical support for such assumption which is also broadly used in the literature since Cornell and Welch (1996), we have still to understand how "homo-accuracy" takes place in real committee deliberation processes to generate gendered (or other minority group) biases outcomes.

\section{APPENDIX}

Proof of Lemma 1: For proving that

$$
W_{\bar{\theta}}(\gamma, p)-W_{\underline{\theta}}(\gamma, p)=\gamma \bar{\theta}\left(\operatorname{Pr}\left(\bar{\theta} \mid s_{H}\right)-\operatorname{Pr}\left(\bar{\theta} \mid s_{L}\right)\right)
$$


is increasing in $\gamma$, it is sufficient to show that $\operatorname{Pr}\left(\bar{\theta} \mid s_{H}\right)$ is increasing in $\gamma$, and $\operatorname{Pr}\left(\bar{\theta} \mid s_{L}\right)$ is decreasing in $\gamma$. Using Bayes rule ${ }^{21}$, we obtain $\operatorname{Pr}\left(\bar{\theta} \mid s_{H}\right)$ and $\operatorname{Pr}\left(\bar{\theta} \mid s_{L}\right)$.

$$
\begin{aligned}
\operatorname{Pr}\left(\bar{\theta} \mid s_{H}\right) & =\frac{\operatorname{Pr}\left(s_{H} \mid \bar{\theta}\right) \operatorname{Pr}(\bar{\theta})}{\operatorname{Pr}\left(s_{H} \mid \bar{\theta}\right) \operatorname{Pr}(\bar{\theta})+\operatorname{Pr}\left(s_{H} \mid \underline{\theta}\right) \operatorname{Pr}(\underline{\theta})} \\
& =\frac{\frac{1+\gamma}{2} p}{\frac{1+\gamma}{2} p+\frac{1-\gamma}{2}(1-p)}=\frac{1}{1+\frac{1-\gamma}{1+\gamma} \frac{1-p}{p}}
\end{aligned}
$$

As $\frac{1-\gamma}{1+\gamma}$ is decreasing in $\gamma$, the whole expression is increasing in $\gamma$.

$$
\begin{aligned}
\operatorname{Pr}\left(\bar{\theta} \mid s_{L}\right) & =\frac{\operatorname{Pr}\left(s_{L} \mid \bar{\theta}\right) \operatorname{Pr}(\bar{\theta})}{\operatorname{Pr}\left(s_{L} \mid \bar{\theta}\right) \operatorname{Pr}(\bar{\theta})+\operatorname{Pr}\left(s_{L} \mid \underline{\theta}\right) \operatorname{Pr}(\underline{\theta})} \\
& =\frac{\frac{1-\gamma}{2} p}{\frac{1-\gamma}{2} p+\frac{1+\gamma}{2}(1-p)}=\frac{1}{1+\frac{1+\gamma}{1-\gamma} \frac{1-p}{p}}
\end{aligned}
$$

As $\frac{1+\gamma}{1-\gamma}$ is increasing in $\gamma$, the whole expression is decreasing in $\gamma$. This concludes the proof.

Proof of Proposition 1: Immediate from the arguments in the main text.

Proof of Proposition 2: Part i) follows from the equilibrium characterization in Proposition 1. Part ii) follows from the proof of Lemma 1 that shows that $w\left(s_{H}\right)=\bar{\theta}\left(\operatorname{Pr}\left(\bar{\theta} \mid s_{H}\right)\right.$ is increasing in $\gamma$ for all priors, and also because

$$
\operatorname{Pr}\left(\bar{\theta} \mid s_{H}\right)=\frac{1}{1+\frac{1-\gamma}{1+\gamma} \frac{1-p}{p}}
$$

is increasing in $p$.

Proof of Lemma 2: This lemma can be proved by construction. If $\gamma_{1}^{f}>\gamma^{*}$, strategic females workers have enough incentives to invest in human capital and then HHC equilibrium arises for both groups in $t=1$ ( since by assumption $\gamma_{1}^{m}>\gamma_{1}^{f}$ ). This equilibrium remains forever, since $\gamma_{t}^{f}=h\left(\frac{1}{2}, \pi\right)>\gamma_{1}^{f}>\gamma^{*}$. If $\gamma_{1}^{f}<\gamma_{1}^{m}<\gamma^{*}$, strategic workers of both groups do not have enough incentives to invest in human capital and then a symmetric LHC equilibria arise in $t=1$. This equilibrium remains forever, since $\gamma_{t}^{m}=h\left(\frac{1}{2}, \pi\right)<\gamma_{1}^{m}<\gamma^{*}$. If $\gamma_{1}^{f}<\gamma^{*}<\gamma_{1}^{m}$, females strategic

\footnotetext{
${ }^{21}$ Concretely

where

$$
\operatorname{Pr}\left(\bar{\theta} \mid s^{H}\right)=\frac{\operatorname{Pr}\left(s^{H} \mid \bar{\theta}\right) \operatorname{Pr}(\bar{\theta})}{\operatorname{Pr}\left(s^{H}\right)}
$$

$$
\operatorname{Pr}\left(s^{H}\right)=\operatorname{Pr}\left(s^{H} \mid \bar{\theta}\right) \operatorname{Pr}(\bar{\theta})+\operatorname{Pr}\left(s^{H} \mid \underline{\theta}\right) \operatorname{Pr}(\underline{\theta})
$$
}


workers do not have enough incentives to invest in human capital but male strategic workers do and then an asymmetric equilibria arise in $t=1$. In $t=2$ the equilibrium is stacionary but there exist three posible steady states. If $h\left(\frac{1-\alpha}{2}, \pi\right)>\gamma^{*}$ both groups have incentives to invest, and the symmetric HHC equilibria will remain forever since $h\left(\frac{1}{2}, \pi\right)>h\left(\frac{1-\alpha}{2}, \pi\right)>\gamma^{*}$. If $h\left(\frac{1+\alpha}{2}, \pi\right)<\gamma^{*}$ both groups do not have incentives to invest, and the symmetric LHC equilibria will remain forever since $\gamma^{*}>h\left(\frac{1+\alpha}{2}, \pi\right)>h\left(\frac{1}{2}, \pi\right)$. Otherwise ( if $h\left(\frac{1-\alpha}{2}, \pi\right)<\gamma^{*}$ and $h\left(\frac{1+\alpha}{2}, \pi\right)>\gamma^{*}$ ), the asymmetric equilibrium arises in $t=2$ and it remains forever since $h\left(\frac{1+\alpha}{2}, \pi\right)>\gamma^{*}>h\left(\frac{1-\alpha}{2}, \pi\right)$.

Proofs of Lemma 3 And Proposition 3: These results follow from the definitions of $\bar{\pi}^{*}, \pi^{*}$ and $\underline{\pi}^{*}$ and the dynamics described in Lemma 2 .

Proof of Proposition 5: Immediate from the arguments in the main text.

Proof of Proposition 6: We have to show that

$$
\gamma^{*}=\left(\frac{\frac{c}{\bar{\theta}}}{1-\alpha^{2}\left(1-\frac{c}{\bar{\theta}}\right)}\right)^{\frac{1}{2}} \geq \gamma^{* *}=\frac{\frac{c}{\bar{\theta}}}{1-\frac{1-\alpha}{2}\left(1-\frac{c}{\bar{\theta}}\right)}
$$

Now, consider $\alpha=0$

$$
\gamma^{*}=\frac{c \frac{1}{2}}{\bar{\theta}} \geq \gamma^{* *}=\frac{2 \stackrel{c}{\bar{\theta}}}{1+\frac{c}{\bar{\theta}}}
$$

We show that this condition is always satisfied when $\frac{c}{\bar{\theta}} \in(0,1)$. This is equivalent to show that $1+a \geq 2 a^{\frac{1}{2}}$ for $a \in(0,1)$. For $a=1$, the LHS=RHS, and the derivative of the LHS=RHS=1. As the RHS is concave, it is not possible that LHS=RHS for $a \in(0,1)$, as the derivate of the RHS for $a \in(0,1)$ is higher than 1 and the derivate of the LHS is one, which would imply that for $a=1$, the LHS $<$ RHS. We have reached a contradiction. Finally, as $\gamma^{*}$ increases with $\alpha$, and $\gamma^{* *}$ decreases with $\alpha, \gamma^{*} \geq \gamma^{* *}$ for all $\alpha \in(0,1)$.

Proof of Proposition 4: As $\pi^{*}$ does not depend on $\rho \cdot\left(\gamma^{*}=h\left(\frac{1}{2}, \pi^{*}\right)\right)$, it is enough to show that $\bar{\pi}^{*}\left(\gamma^{*}=h\left(\frac{(1-\alpha) \rho}{(1-\alpha) \rho+(1+\alpha)(1-\rho)}, \bar{\pi}^{*}\right)\right)$ is decreasing on $\rho$. Let $f$ be $\frac{(1-\alpha) \rho}{(1-\alpha) \rho+(1+\alpha)(1-\rho)}$. By definition, we know that $\frac{\partial h}{\partial f}>0$ and $\frac{\partial h}{\partial \bar{\pi}^{*}}>0$. Finally

$$
\begin{aligned}
\frac{\partial f}{\partial \rho} & =\frac{(1-\alpha)^{2} \rho+\left(1-\alpha^{2}\right)(1-\rho)-(1-\alpha)^{2} \rho+\left(1-\alpha^{2}\right) \rho}{((1-\alpha) \rho+(1+\alpha)(1-\rho))^{2}} \\
& =\frac{\left(1-\alpha^{2}\right)}{((1-\alpha) \rho+(1+\alpha)(1-\rho))^{2}}>0
\end{aligned}
$$


Then, taking the total derivative, we can compute $\frac{\partial \bar{\pi}^{*}}{\partial \rho}=-\frac{\frac{\partial h}{\partial f} \frac{\partial h}{\partial f}}{\frac{\partial h}{\partial \bar{\pi}^{*}}}<0$.

Proof of Proposition 7: Consider that a high productivity woman is evaluated (the proof of the low productivity type goes along the same lines) and $\phi^{f}=\frac{m+1}{N}>\phi^{f^{\prime}}=\frac{m}{N}$ we have to prove that $\sum_{R=0}^{n} \operatorname{Pr}(R \mid \bar{\theta})_{\phi^{f}} \leq \sum_{R=0}^{n} \operatorname{Pr}(R \mid \bar{\theta})_{\phi^{\prime}{ }^{\prime}}$ for an arbitrary $n \leq N$. For transitivity, it is enough to show that the lemma hold when one woman $j$ replaces one man $j$ in the committee. Given that $\operatorname{Pr}\left\{r_{j}=1 \mid \theta_{f}=\bar{\theta}\right\}_{f}=\bar{\beta}>\operatorname{Pr}\left\{r_{j}=1 \mid \theta_{m}=\bar{\theta}\right\}_{m}=\beta$, the probability that the sum of votes of all committee members but $j$ is $R$ is $\operatorname{Pr}(R \mid \bar{\theta})_{\phi_{f}}=\bar{\beta} \operatorname{Pr}_{C / j}(R-1 \mid \bar{\theta})_{\phi_{f}}+(1-\bar{\beta}) \operatorname{Pr}_{C / j}(R \mid \bar{\theta})_{\phi f}$ and $\operatorname{Pr}(R \mid \bar{\theta})_{\phi^{f} f^{\prime}}=\underline{\beta} \operatorname{Pr}_{C / j}(R-1 \mid \bar{\theta})_{\phi^{f^{\prime}}}+(1-\underline{\beta}) \operatorname{Pr}_{C / j}(R \mid \bar{\theta})_{\phi^{f^{\prime}}}$. By construction, $\operatorname{Pr}_{C / j}(R \mid \bar{\theta})_{\phi^{f}}=$ $\operatorname{Pr}_{C / j}(R \mid \bar{\theta})_{\phi^{f^{\prime}}}$ and $\operatorname{Pr}_{C / j}(R-1 \mid \bar{\theta})_{\phi^{f}}=\operatorname{Pr}_{C / j}(R-1 \mid \bar{\theta})_{\phi^{f^{\prime}}}$. Then

$$
\begin{aligned}
& \sum_{R=0}^{n} \operatorname{Pr}(R \mid \bar{\theta})_{\phi^{f}}-\sum_{R=0}^{n} \operatorname{Pr}(R \mid \bar{\theta})_{\phi^{f}{ }^{\prime}} \quad= \\
& -(\bar{\beta}-\underline{\beta}) \underset{C / j}{\operatorname{Pr}}(0 \mid \bar{\theta})_{\phi^{f}}+\sum_{R=1}^{n}\left((\bar{\beta}-\underline{\beta}) \underset{C / j}{\operatorname{Pr}}(R-1 \mid \bar{\theta})_{\phi^{f}}-(\bar{\beta}-\underline{\beta}) \underset{C / j}{\operatorname{Pr}}(R \mid \bar{\theta})_{\phi^{f}}\right)= \\
& -(\bar{\beta}-\underline{\beta}) \operatorname{Pr}_{C / j}(n \mid \bar{\theta})_{\phi^{f}} \leq 0
\end{aligned}
$$

Notice that for each value of $R$ in the summatory, the first term of $R-1$ cancels out with the second term of $R$ of $n-1$. This applies to all terms but the last one. This concludes the proof.

Proof of Corollary 8: It is a direct application of Proposition 7.

Proof of Lemma 4: We have to adapt the proof of Lemma 1 to the asymmetric information structure of the voting subsection

\begin{tabular}{r|cc}
$\operatorname{Pr}(s \mid \theta)$ & $\bar{\theta}$ & $\underline{\theta}$ \\
\hline$s_{H}$ & $\gamma_{\bar{\theta}}$ & $1-\gamma_{\underline{\theta}}$ \\
$s_{L}$ & $1-\gamma_{\bar{\theta}}$ & $\gamma_{\underline{\theta}}$
\end{tabular}

As the incremental expected pay-off between high and low productivity is as follow

$$
W_{\bar{\theta}}\left(\gamma_{\bar{\theta}}, \gamma_{\underline{\theta}}, p\right)-W_{\underline{\theta}}\left(\gamma_{\bar{\theta}}, \gamma_{\underline{\theta}}, p\right)=\left(\gamma_{\bar{\theta}}+\gamma_{\underline{\theta}}-1\right) \bar{\theta}\left(\operatorname{Pr}\left(\bar{\theta} \mid s_{H}\right)-\operatorname{Pr}\left(\bar{\theta} \mid s_{L}\right)\right)
$$

it is sufficient to show that $\operatorname{Pr}\left(\bar{\theta} \mid s_{H}\right)$ is increasing in $\gamma_{\bar{\theta}}$ and $\gamma_{\underline{\theta}}$, and $\operatorname{Pr}\left(\bar{\theta} \mid s_{L}\right)$ is decreasing in $\gamma_{\bar{\theta}}$ and $\gamma_{\underline{\theta}}$. Using Bayes rule, we obtain $\operatorname{Pr}\left(\bar{\theta} \mid s_{H}\right)$ and $\operatorname{Pr}\left(\bar{\theta} \mid s_{L}\right)$.

$$
\operatorname{Pr}\left(\bar{\theta} \mid s_{H}\right)=\frac{\operatorname{Pr}\left(s_{H} \mid \bar{\theta}\right) \operatorname{Pr}(\bar{\theta})}{\operatorname{Pr}\left(s_{H} \mid \bar{\theta}\right) \operatorname{Pr}(\bar{\theta})+\operatorname{Pr}\left(s_{H} \mid \underline{\theta}\right) \operatorname{Pr}(\underline{\theta})}=\frac{\gamma_{\bar{\theta}} p}{\gamma_{\bar{\theta}} p+\left(1-\gamma_{\underline{\theta}}\right)(1-p)}
$$


As the denominator decreases in $\gamma_{\underline{\theta}}$, the whole expression is increasing in $\gamma_{\underline{\theta}}$. Differentiating $\operatorname{Pr}\left(\bar{\theta} \mid s_{H}\right)$,

$$
\frac{\partial \operatorname{Pr}\left(\bar{\theta} \mid s_{H}\right)}{\partial \gamma_{\bar{\theta}}}=\frac{\left(1-\gamma_{\underline{\theta}}\right)(1-p) p}{\left(\gamma_{\bar{\theta}} p+\left(1-\gamma_{\underline{\theta}}\right)(1-p)\right)^{2}} \geq 0
$$

Similarly

$$
\operatorname{Pr}\left(\bar{\theta} \mid s_{L}\right)=\frac{\operatorname{Pr}\left(s_{L} \mid \bar{\theta}\right) \operatorname{Pr}(\bar{\theta})}{\operatorname{Pr}\left(s_{L} \mid \bar{\theta}\right) \operatorname{Pr}(\bar{\theta})+\operatorname{Pr}\left(s_{L} \mid \underline{\theta}\right) \operatorname{Pr}(\underline{\theta})}=\frac{\left(1-\gamma_{\bar{\theta}}\right) p}{\left(1-\gamma_{\bar{\theta}}\right) p+\gamma_{\underline{\theta}}(1-p)}
$$

As the denominator increases in $\gamma_{\underline{\theta}}$, the whole expresion is decreasing in $\gamma_{\underline{\theta}}$. Differentiating $\operatorname{Pr}\left(\bar{\theta} \mid s_{L}\right)$,

$$
\frac{\partial \operatorname{Pr}\left(\bar{\theta} \mid s_{L}\right)}{\partial \gamma_{\bar{\theta}}}=\frac{-\gamma_{\underline{\theta}}(1-p) p}{\left(\left(1-\gamma_{\bar{\theta}}\right) p+\gamma_{\underline{\theta}}(1-p)\right)^{2}} \leq 0
$$

Proof of Proposition 9: It is a direct proof, using equation 8 and that $h(1, \pi)=1$ and $h(0, \pi)=0$.

Proof of Proposition 10: The first order condition is

$$
\left(1-\frac{2 h\left(\phi^{f}, \pi\right)}{1+h\left(\phi^{f}, \pi\right)}\right) \frac{h^{\prime}\left(\phi^{f}, \pi\right)}{\left(1+h\left(\phi^{f}, \pi\right)\right)^{2}}=\left(1-\frac{2 h\left(1-\phi^{f}, \pi\right)}{1+h\left(1-\phi^{f}, \pi\right)}\right) \frac{h^{\prime}\left(1-\phi^{f}, \pi\right)}{\left(1+h\left(1-\phi^{f}, \pi\right)\right)^{2}}
$$

it is convenient to express the FOC as

$$
\frac{\left(1-\frac{2 h\left(\phi^{f}, \pi\right)}{1+h\left(\phi^{f}, \pi\right)}\right) \frac{1}{\left(1+h\left(\phi^{f}, \pi\right)\right)^{2}}}{\left(1-\frac{2 h\left(1-\phi^{f}, \pi\right)}{1+h\left(1-\phi^{f}, \pi\right)}\right) \frac{1}{\left(1+h\left(1-\phi^{f}, \pi\right)\right)^{2}}}=\frac{h^{\prime}\left(1-\phi^{f}, \pi\right)}{h^{\prime}\left(\phi^{f}, \pi\right)}
$$

The LHS is decreasing in $\phi^{f}$, the RHD is increasing if $h^{\prime \prime}<0$ and decreasing if $h^{\prime \prime}>0$.

Then there is only one possible solution if $h^{\prime \prime}<0$, and this is that $h\left(1-\phi^{f}, \pi\right)=h\left(\phi^{f}, \pi\right)$ and $\left(1-\phi^{f}\right)=\phi^{f}=\frac{1}{2}$. In fact, $\left(1-\phi^{f}\right)=\phi^{f}=\frac{1}{2}$ is always a solution of the FOC, but whether or not this is the optimal solution of the problem depends on the second order condition.

The second order condition is also satisfied when $h\left(\phi^{f}, \pi\right)$ is concave since all terms are negative.

$$
\begin{aligned}
& {\left[\left(1-\frac{2 h\left(\phi^{f}, \pi\right)}{1+h\left(\phi^{f}, \pi\right)}\right) \frac{1}{\left(1+h\left(\phi^{f}, \pi\right)\right)^{2}}\right]^{\prime} h^{\prime}\left(\phi^{f}, \pi\right)+\left[\left(1-\frac{2 h\left(\phi^{f}, \pi\right)}{1+h\left(\phi^{f}, \pi\right)}\right) \frac{h^{\prime \prime}\left(\phi^{f}, \pi\right)}{\left(1+h\left(\phi^{f}, \pi\right)\right)^{2}}\right]+} \\
& -\left[\left(1-\frac{2 h\left(1-\phi^{f}, \pi\right)}{1+h\left(1-\phi^{f}, \pi\right)}\right) \frac{1}{\left(1+h\left(1-\phi^{f}, \pi\right)\right)^{2}}\right]^{\prime} h^{\prime}\left(1-\phi^{f}, \pi\right)+\left[\left(1-\frac{2 h\left(1-\phi^{f}, \pi\right)}{1+h\left(1-\phi^{f}, \pi\right)}\right) \frac{h^{\prime}\left(1-\phi^{f}, \pi\right)}{\left(1+h\left(1-\phi^{f}, \pi\right)\right)^{2}}\right]
\end{aligned}
$$


This concludes the proof.

Proof of Proposition 11: $h\left(\frac{1}{2}, \pi\right)$ is increasing and concave. Take $h(0, \pi)=b$ and $h\left(\frac{1}{2}, \pi\right)=a$ as given. The concave function that maximizes the slope at $\frac{1}{2}$ and crosses these two points is the linear function $b+2(a-b) x$. Then, the maximum possible slope (with $b=0)$ at $\frac{1}{2}$ is $2 a=2 h\left(\frac{1}{2}, \pi\right)$. Replacing $h^{\prime}\left(\frac{1}{2}, \pi\right)$ in the stability condition by the maximun slope $2 h\left(\frac{1}{2}, \pi\right)$, we obtain

$$
\frac{2 h\left(\frac{1}{2}, \pi\right)}{2 h\left(\frac{1}{2}, \pi\right)\left(1+h\left(\frac{1}{2}, \pi\right)\right)}=\frac{1}{\left(1+h\left(\frac{1}{2}, \pi\right)\right)}<1
$$

Then, the stability condition (9) always holds for any concave $h(\phi, \pi)$ function.

\section{Appendix B}

\section{Asymmetric Information Structures and Multiplicity of Equilibria}

We consider an asymmetric information structure. The signal's realization $s \in\left\{s_{H}, s_{L}\right\}$ depends on the underlying productivity of the worker, as follows:

\begin{tabular}{r|cc}
$\operatorname{Pr}(s \mid \theta)$ & $\bar{\theta}$ & $\underline{\theta}$ \\
\hline$s_{H}$ & 1 & $1-\gamma$ \\
$s_{L}$ & 0 & $\gamma$
\end{tabular}

That is, if the worker has high productivity, the signal will be $s_{H}$ with certainty. However, if the productivity is low, there is some noise and thus both signal realizations may take place. As in the main model, $\gamma$ represents the accuracy of the signal, with a higher $\gamma$ implying a more informative signal. Interestingly, with this information structure, a bad realization is fully revealing, $\left.\operatorname{Pr}\left(\bar{\theta} \mid s_{L}\right)\right)=0$.

Under this information structure, the expected payoff of high and low productivity are

$$
\begin{aligned}
& W_{\bar{\theta}}(\gamma, p)=w\left(s_{H}\right) \\
& W_{\underline{\theta}}(\gamma, p)=\gamma w\left(s_{L}\right)+(1-\gamma) w\left(s_{H}\right)
\end{aligned}
$$

As in the main model, the incentives to invest in human capital are driven by the incremental expected pay-off between high and low productivity.

$$
W_{\bar{\theta}}(\gamma, p)-W_{\underline{\theta}}(\gamma, p)=\gamma\left(w\left(s_{H}\right)-w\left(s_{L}\right)\right)=\gamma \bar{\theta}\left(\operatorname{Pr}\left(\bar{\theta} \mid s_{H}\right)-\operatorname{Pr}\left(\bar{\theta} \mid s_{L}\right)\right)=\gamma \bar{\theta} \operatorname{Pr}\left(\bar{\theta} \mid s_{H}\right)
$$


As in the main model, the incentive compatibility condition of the HHC equilibrium is

$$
W_{\bar{\theta}}\left(\gamma, \frac{1+\alpha}{2}\right)-W_{\underline{\theta}}\left(\gamma, \frac{1+\alpha}{2}\right) \geq \widehat{c} .
$$

We can rewrite this incentive compatibility condition in terms of $\gamma,{ }^{22}$ as follows:

$$
\gamma \geq \underline{\gamma}^{A}=\frac{2}{(1+\alpha) \frac{\bar{\theta}}{\bar{c}}+(1-\alpha)}
$$

Similarly, the incentive compatibility condition of the LHC equilibrium is

$$
W_{\bar{\theta}}\left(\gamma, \frac{1-\alpha}{2}\right)-W_{\underline{\theta}}\left(\gamma, \frac{1-\alpha}{2}\right) \geq \widehat{c} .
$$

We can rewrite this incentive compatibility condition in terms of $\gamma,{ }^{23}$ as follows:

$$
\gamma \leq \bar{\gamma}^{A}=\frac{2}{(1-\alpha) \frac{\bar{\theta}}{\bar{c}}+(1+\alpha)}
$$

As $\bar{\gamma}^{A}>\underline{\gamma}^{A}$, if $\underline{\gamma}^{A}<\gamma<\bar{\gamma}^{A}$ then a LHC and HHC equilibrium exists (multiplicity of equilibria arise). Figure 4 provides the full characterization of equilibria in pure strategies.

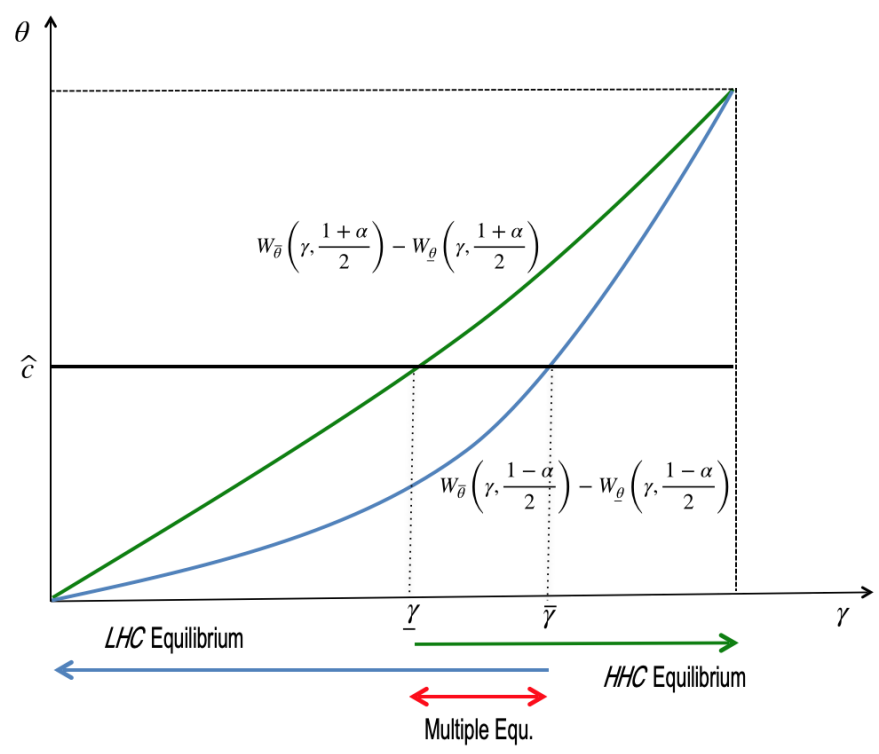

Figure 4. Asymmetric Information Structure and Multiplicity of Equilibria.

\footnotetext{
${ }^{22}$ Applying Bayes' rule, $\operatorname{Pr}\left(\bar{\theta} \mid s_{H}\right)=\frac{\operatorname{Pr}\left(s_{H} \mid \bar{\theta}\right) \operatorname{Pr}(\bar{\theta})}{\operatorname{Pr}\left(s_{H} \mid \bar{\theta}\right) \operatorname{Pr}(\bar{\theta})+\operatorname{Pr}\left(s_{H} \mid \bar{\theta}\right) \operatorname{Pr}(\underline{\theta})}=\frac{\frac{1+\alpha}{2}}{\frac{1+\alpha}{2}+(1-\gamma) \frac{1-\alpha}{2}}$. The incentive compatibility condition becomes $\frac{\gamma(1+\alpha) \bar{\theta}}{2-\gamma(1-\alpha)} \geq \widehat{c}$. As left hand side is increasing in $\gamma$, we can rewrite the incentive compatibility condition in terms $\gamma$, and $\underline{\gamma}^{A}$ is characterize .

${ }^{23}$ Similarly to the previous case, we apply the Bayes' rule, $\operatorname{Pr}\left(\bar{\theta} \mid s_{H}\right)=\frac{\operatorname{Pr}\left(s_{H} \mid \bar{\theta}\right) \operatorname{Pr}(\bar{\theta})}{\operatorname{Pr}\left(s_{H} \mid \bar{\theta}\right) \operatorname{Pr}(\bar{\theta})+\operatorname{Pr}\left(s_{H} \mid \underline{\bar{\theta}}\right) \operatorname{Pr}(\underline{\theta})}=\frac{\frac{1-\alpha}{2}}{\frac{1-\alpha}{2}+(1-\gamma) \frac{1+\alpha}{2}}$ and rewrite the incentive compatibility condition $\frac{\gamma(1-\alpha) \bar{\theta}}{2-\gamma(1+\alpha)} \leq \widehat{c}$.
} 


\section{REFERENCES}

[1] Aigner, D. J. and Cain, G. (1977). "Statistical theories of discrimination in labor markets", Industrial and Labor relations review 30(2), 175-187.

[2] Altonji, J.G. and Pierret, C.R. (2001). "Employer Learning and Statistical Discrimination", The Quarterly Journal of Economics, 116(1), 313-350.

[3] Arrow, K. J. (1973). "The Theory of Discrimination", in Ashenfelter, O. and Rees, A. (eds), Discrimination in Labor Markets, Princeton University Press 3-33.

[4] Athey, S., Avery, C., and Zemsky, P. (2000). "Mentoring and Diversity", American Economic Review, 90, 4, 765-786.

[5] Austen-Smith, D. and Feddersen, T.J. (2009). "Information aggregation and communication in committees", Philosophical Transactions of the Royal Society B: Biological Sciences, 364, $763-769$.

[6] Austen-Smith, D. and Banks, J.S. (1996). "Information aggregation, rationality, and the Condorcet Jury Theorem." American Political Science Review, 90, 34-45.

[7] Azmat, G. and Ferrer, R. (2017). "Gender Gaps in Performance: Evidence from Young Lawyers", Journal of Political Economy, 125, 5.

[8] Becker, G. (1975). Human Capital: A Theoretical and Empirical Analysis with special reference to Education, University of Chicago Press.

[9] Bertrand, M., Goldin, C. and Katz, L. (2010). "Dynamics of the Gender Gap for Young Professionals in the Financial and Corporate Sectors.", American Economic Journal: Applied Economics, 2(3), 228-55.

[10] Besley, T., Folke, O., Persson, T. and Rickne, J. (2017). "Gender Quotas and the Crisis of the Mediocre Men: Theory and evidence from Sweden", American Economic Review, 107 (8), 2204-42. 
[11] Booth, A., M. Francesconi, and Frank, J. (2003). "A Sticky Floors Model of Promotion, Gender and Pay". European Economic Review 47 (2), 295- 322.

[12] Bohren, J. A, A. Imas, and Rosenberg, M. (2019). "The Dynamics of Discrimination, Theory and Evidence," American Economic Review, 109, 3395-3436.

[13] Bordalo, P., K. Coffman, and Gennaioli, N. (2019) "Beliefs about Gender," American Economic Review, 109, 739-773.

[14] Coate, S. and Loury, G. C. (1993). "Will Affirmative-Action Policies Eliminate Negative Stereotypes?", American Economic Review, 83(5), 1220-1240.

[15] Cornelll, B. and Welch, I. (1996). "Culture Information and Screening Discrimination", Journal of Political Economy 104 (3): 542-571.

[16] Coughlan, P.J. (2000). "In Defense of Unanimous Jury Verdicts: Mistrials, Communication, and Strategic Voting", American Political Science Review, 94(2), 375-93.

[17] Diamond, D. W. (1989). "Reputation Acquisition in Debt Markets", The Journal of Political Economy, 97(4), 828-862.

[18] Feddersen, T.J. and Pesendorfer, W. (1996). "The Swing Voter's Curse", The American Economic Review, 86 (3), 408-424.

[19] Feddersen, T.J. and Pesendorfer, W. (1997). "Voting Behavior and Information Aggregation in Elections with Private Information", Econometrica, 65(5), 1029-58.

[20] Ferrari, G., Mac Millan, R. and Profeta, P. (2015) "Is There Gender Bias in Candidate Selection? Experimental Evidence from Italy", Università Bocconi mimeo.

[21] Flabbi, L. ; Macis, M; Moro, A. and F. Schivardi (2019)"Do Female Executives Make a Difference? The Impact of Female Leadership on Gender Gaps and Firm Performance", Economic Journal, 129(622): 2390-2423, 2019. 
[22] Foster, D.P. and Vohra, R.V. (1992). "An Economic Argument for Affirmative Action.", Rationality and Society, 4(2), 176-88.

[23] Goldin, C. and Rouse. C. (2000). "Orchestrating Impartiality: the Impact of 'Blind'Auditions on Female Musicians", American Economic Review 90(4), 715-741.

[24] Kahn, L. and Lange, F. (2014). "Employer Learning, Productivity, and the Earnings Distribution: Evidence from Performance Measures ", The Review of Economic Studies 81(4), Pages 1575-1613.

[25] Kevin, L. (1986) "A Language Theory of Discrimination" The Quarterly Journal of Economics, Volume 101, Issue 2, May 1986, pp: 363-382.

[26] Lang, K and Spitzer, AKL (2020) "Race Discrimination: An Economic Perspective", Journal of Economic Perspectives, 34 (2), 68-89.

[27] Lesner,R. (2018) “Testing for Statistical Discrimination Based on Gender",Labour 32 (2), $141-181$.

[28] Lundberg, S. J. and Startz, R. (1983) "Private Discrimination and Social Intervention in Competitive Labor Markets", American Economic Review, 73(3), 340-347.

[29] Mailath, G., L. Samuelson and A. Shaked (2000), "Endogenous Inequality in Integrated Labor Markets with Two-Sided Search", American Economic Review, 90 (1), 46-72.

[30] Matsa, D. A. and Miller, A. (2011) "Chipping Away at the Glass Ceiling: Gender Spillovers in Corporate Leadership", American Economic Review. P\&P. 101(3), 635-639.

[31] Mengel, F. (2019) "Gender Biases in Opinion Aggregation", working paper, University of Essex.

[32] Morgan, J and Várdy, F. (2009). "Diversity in the Workplace.” American Economic Review, $99(1), 472-85$. 
[33] Moro, A. and Norman, P. (2004). "A General Equilibrium Model of Statistical Discrimination", Journal of Economic Theory 114(1), 1-30.

[34] Fang, H and Moro, A. (2011) "Theories of statistical discrimination and affirmative action: A survey." Handbook of social economics, North-Holland, 133-200

[35] Niederle, M., and Vesterlund, L. (2010). "Explaining the Gender Gap in Math Test Scores: The Role of Competition", The Journal of Economic Perspectives, 24 (2), 129-44.

[36] Osborne, M., Rosenthal, J. and Stewart, C. (2020) "Information Aggregation with Costly Reporting", The Economic Journal, 130, 208-232.

[37] Pallais, A. (2014). "Inefficient Hiring in Entry-Level Labor Markets." American Economic Review, 104, (11), 3565-99.

[38] Phelps, E. (1972). "The Statistical Theory of Racism and Sexism", American Economic Review, 62(4), 659-661.

[39] Pinkston, J. (2003). "Screening Discrimination and the Determinants of Wages", Labour Economics 10(6), 643-658.

[40] Pinkston, J. (2009). "A Model of Asymmetric Employer Learning with Testable Implications", The Review of Economic Studies 76(1), 367-394.

[41] Reuben, E, P. Sapienza, and Zingales, L. (2014) “How Stereotypes Impair Women's Careers in Science," Proceedings of theNational Academy of Sciences, 111, 4403-4408.

[42] Roland G. F., Jr., D. Pager, and Spenkuch, J. (2013). "Racial Disparities in Job Finding and Offered Wages". Journal of Law and Economics, 56, 633-689.

[43] Roux, N and Sobel, J. (2015) "Group Polarization in a Model of Information Aggregation", American Economic Journal: Micreeconomics, 7(4), 202-32.

[44] Schonberg, U. (2007) "Testing for Asymmetric Employer Learning", Journal of Labor Economics 25, 651-691. 
[45] Siniscalchi, M and Veronesi, P. (2020) "Self-Image Bias and Lost Talent", CEPR Discussion Paper Series DP15621.

[46] Small, M. and Pager, D. (2020) "Sociological Perspectives on Racial Discrimination", Journal of Economic Perspectives, 34 (2), 49-67.

[47] World Economic Forum, Global Gender Gap Report 2020, available at: http://www3.weforum.org/docs/WEF_GGGR_2020.pdf 